NBER WORKING PAPER SERIES

\title{
DYNAMIC PRICE COMPETITION, LEARNING-BY-DOING AND STRATEGIC BUYERS
}

\author{
Andrew Sweeting \\ Dun Jia \\ Shen Hui \\ Xinlu Yao \\ Working Paper 28272 \\ http://www.nber.org/papers/w28272 \\ NATIONAL BUREAU OF ECONOMIC RESEARCH \\ 1050 Massachusetts Avenue \\ Cambridge, MA 02138 \\ December 2020
}

This paper was written while Andrew Sweeting was serving as Director of the Bureau of Economics at the Federal Trade Commission (FTC). The views expressed are those of the authors, and do not reflect the views of the FTC, its staff or any individual Commissioner. We are very grateful to Uli Doraszelski and Steve Kryukov for access to their computational results which helped to confirm our own results with non-strategic buyers. We are also very grateful to David Besanko and Uli Doraszelski for insightful comments, as well as to conference and seminar participants at Penn State, the FTC and the Washington DC IO conference. All errors are our own. We have no material or relevant financial relationships to disclosure. The views expressed herein are those of the authors and do not necessarily reflect the views of the National Bureau of Economic Research.

NBER working papers are circulated for discussion and comment purposes. They have not been peer-reviewed or been subject to the review by the NBER Board of Directors that accompanies official NBER publications.

(C) 2020 by Andrew Sweeting, Dun Jia, Shen Hui, and Xinlu Yao. All rights reserved. Short sections of text, not to exceed two paragraphs, may be quoted without explicit permission provided that full credit, including $\odot$ notice, is given to the source. 
Dynamic Price Competition, Learning-By-Doing and Strategic Buyers

Andrew Sweeting, Dun Jia, Shen Hui, and Xinlu Yao

NBER Working Paper No. 28272

December 2020

JEL No. C73,D21,D43,L13,L41

\section{ABSTRACT}

We generalize recent models of dynamic price competition where sellers benefit from learningby-doing by allowing for long-lived strategic buyers, with a single parameter capturing the extent to which each buyer internalizes future buyer surplus. Many of the equilibria that exist when buyers are atomistic or myopic are eliminated when buyers internalize even a modest share of their effects on future surplus. The equilibria that survive tend to be those where long-run market competition is preserved.

Andrew Sweeting

Department of Economics

University of Maryland

Tydings Hall 3135

College Park, MD 20742

and NBER

sweeting@econ.umd.edu

Dun Jia

Renmin University of China

59 Zhongguancun Street

Haidian District

Beijing 100872

China

calvin.dun.jia@gmail.com
Shen Hui

School of Management and Economics

The Chinese University of Hong Kong, Shenzhen Shenzhen

China

huishen@cuhk.edu.cn

Xinlu Yao

Department of Economics

University of Maryland

Tydings Hall

College Park, MD 20742

yao@econ.umd.edu

A data appendix is available at http://www.nber.org/data-appendix/w28272 


\section{Introduction}

In industries where firms benefit from learning-by-doing (LBD), there is a natural tension between achieving productive efficiency, which will require concentrating production at a single producer, and sustaining competition, which may require spreading production across multiple firms. Economists have analyzed a range of models to understand whether unregulated market equilibria will sustain competition, how efficient these equilibria are and how surplus is split between customers and producers.

One literature has used analytical theory to consider models where there are two competing suppliers and a single long-lived buyer who purchases a single unit each period and cannot commit to long-run contracts (Lewis and Yildirim (2002) $) 4^{1}$ The Lewis and Yildirim model has a unique Markov Perfect equilibrium where the monopsonist spreads its purchases across duopolists to maintain competition, although this strategy can raise prices as sellers have weaker incentives to gain an advantage.

A second literature also models two competing suppliers with a single unit sold each period, but assumes that buyers are atomistic or, equivalently, that buyers make purchase decisions myopically. Most notably, Cabral and Riordan (1994) consider a model where duopolists sell differentiated products, cost reductions stop once a certain level of cumulative sales is reached and there is an infinite sequence of short-lived buyers with heterogeneous preferences over the sellers. They show that when a supplier may choose to exit, equilibria where firms price aggressively to try to drive their rival out of the market can exist, and markets can tend towards monopoly.

This observation has led David Besanko and co-authors to use computational methods to analyze, in a systematic way, Markov Perfect equilibrium behavior in an enriched version of the Cabral and Riordan model, which we will call the "BDK model", while maintaining the assumption of short-lived buyers (Besanko, Doraszelski, and Kryukov (2014) (BDK1) and Besanko, Doraszelski, and Kryukov (2019) (BDK2)). Besanko, Doraszelski, Kryukov, and Satterthwaite 2010) (BDKS) consider a related model where exit is not possible but a firm's experience can stochastically decay ("forgetting") when it does not make a sale, consistent

\footnotetext{
1 Lewis and Yildirim (2005) and Anton, Biglaiser, and Vettas (2014) provide related models where a monopsonist strategic buyer seeks to maintain competition between duopolist suppliers. Saini (2012) shows similar qualitative effects in a computational model of repeated procurement.
} 
with the empirical evidence of forgetting identified by Benkard (2000). Forgetting and exit both create the possibility that a rival firm will move up its cost curve in the future.

The key conclusions that these papers draw is that it is the "norm rather than the exception" (BDK1, p. 888) for these models to have multiple, and often very many, equilibria, and that aggressive equilibria that may tend to produce sustained monopoly, and higher long-run prices, commonly exist, and often coexist with equilibria where competition is certain to be maintained.

The fact that the conclusions drawn from models with atomistic buyers and monopsony can be so different raises the question of what happens when we allow for both assumptions in the same model, and when we consider intermediate cases, with multiple forward-looking repeat buyers. These questions are interesting theoretically, but also practically as many of the industries where LBD has been documented, such as aircraft manufacture Alchian (1963), Benkard (2000)), power plants (Zimmerman (1982)), shipbuilding (Thompson (2001), Thornton and Thompson (2001)), semiconductors (Irwin and Klenow (1994), Dick (1991)) and chemicals (Lieberman (1984), Lieberman (1987)), have at least some large and repeat customers $\mathrm{I}^{2}$ For example, for civilian aircraft, a small number of carriers often account for a significant share of the orders for particular models and it is common for the world's largest carriers and aircraft leasing companies to buy significant numbers of similar types of planes sold by different manufacturers $!^{3}$

In this paper we extend the BDK and BDKS models to allow for long-lived strategic buyers. We assume that buyers are long-lived and we specify a single parameter $\left(b^{p}\right)$ that measures each buyer's expected share of future buyer surplus, so that the atomistic and monopsonistic assumptions are polar cases. We study, in detail, what happens to strategies, prices and welfare as we vary this parameter.

We find that as buyers become more strategic, equilibrium multiplicity tends to be elimi-

\footnotetext{
${ }^{2}$ Even in the case of hospital procedures (Gaynor, Seider, and Vogt (2005), Dafny (2005)) where an individual patient may hope to only purchase the service once, their choices are influenced by physician groups and payers that know they will be dealing with similar patients in the future.

${ }^{3}$ For example, by July 2020242 Airbus A380s have been delivered to 14 different buyers, with a buyerside HHI (based on the number of aircraft sold to different airlines) of 0.239 (source, accessed July 18, 2020: https://en.wikipedia.org/wiki/List_of_Airbus_A380_orders_and_deliveries). Details on fleets by carrier in May 2019 reported by Air Transport World (July/August 2019 edition, pages 45-55, accessed August 16, 2020). For example, Delta's fleet included 213 Boeing 737s and 62 Airbus A320s. Of course, some carriers, such as Southwest are known to purchase planes from a single manufacturer (in this case, Boeing).
} 
nated, and that for parameters for which, with atomistic buyers, equilibria that can give rise to long-run dominance coexist with equilibria that always result in long-run competition, it is the equilibria with long-run competition that tend to survive. As a result, strategic buyers tend to lower expected long-run prices, although, when both firms start at the top of their learning curves, the net present value (NPV) of buyer welfare can be reduced when buyers act strategically as the initial competition between sellers to gain an advantage is softened. While these qualitative results might be expected given what we know about the incentives of a monpsonist, we find that multiplicity can be eliminated even when buyers only expect to receive a small proportion of future buyer surplus, which, in our framework, can be viewed as equivalent to the buyer-side of the market being relatively unconcentrated. This elimination of multiplicity for low levels of $b^{p}$ is a particular feature of our extension of the BDKS model.

One implication of existing research in which equilibria where a single firm can establish dominance through aggressive pricing can exist, is that claims of "predatory pricing", where a potentially competitive firm is forced to exit, may be plausible. Claims of predation are often hard to evaluate, and our results suggest that they may be less plausible when the buyer-side of a market is even moderately concentrated $!^{4}$

Our paper also contributes to the emerging literatures in both economics and management science that consider how larger and more sophisticated buyers can affect how markets work (for example, Jerath, Netessine, and Veeraraghavan (2010), Hörner and Samuelson (2011), Board and Skrzypacz (2016), Chen, Farias, and Trichakis (2019) and, motivated by antitrust analysis, Loertscher and Marx (2019)). In particular, we show how even limited strategic buyer behavior affects outcomes in an infinite horizon model that has quite rich supply-side competitive dynamics. Our results also suggest that empirical analyses of industries with LBD where atomistic buyers have been assumed for convenience (for example, Benkard (2004) and Kim (2014) ) could give different results if strategic buyer behavior was accounted for. More encouragingly, however, our results also suggest that allowing for strategic buyer behavior may not only add realism to empirical analyses, but also reduce concerns that the possibility of multiple equilibria, which is often hard to detect, may undermine the researcher's ability

\footnotetext{
${ }^{4}$ Of course, if we added features, such as financial constraints or asymmetric information, that are not features of the Cabral and Riordan (1994), BDKS or BDK models, or the models considered here, it may be that predatory equilibria could re-emerge. This is an important topic for future research.
} 
to interpret structural counterfactuals.

We also make one methodological contribution. Much of our analysis will follow the Besanko et al. approach of using homotopies to identify the set of equilibria. However, homotopies are not guaranteed to find all equilibria, so one might doubt claims of uniqueness based only on homotopies. In the context of the BDK model, we develop a novel recursive, backwards induction algorithm that provides a way to prove whether or not equilibria where, once a certain point in the game has been reached, exit will result in permanent monopoly, exist. We use this approach to provide supporting evidence of equilibrium uniqueness, and, because the results from our homotopy analysis and this method turn out to be perfectly consistent, it also provides new evidence that the homotopy approach works in practice. We believe that the method will also be useful in the next step of this research where we plan to relax some of the assumptions from the earlier literature, such as the ex-ante symmetry of buyers, that we continue to maintain in this paper.5

The rest of the paper proceeds as follows. Section 2 describes our extended version of the BDK model and the methods used to identify equilibria. Section 3 provides the intuition for why strategic buyer behavior of the type that we model changes equilibrium behavior using a single set of parameters. Section 4 gives our results on existence, market outcomes and welfare in the BDK model for a range of parameters. Section 5 presents the results for our extended BDKS model. Section 6 concludes. The Appendices contain details of the methodology, and some additional results and figures.

\section{The Extended BDK Model}

In this section we present our extended version of the BDK model. Readers should consult BDK1 and BDK2 for additional discussion of the original model. Section 5 will describe the differences between the BDK and the BDKS model.

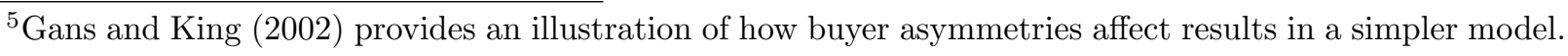




\subsection{States and Costs.}

We consider an infinite horizon, discrete time, discrete state game between two ex-ante symmetric price-setting firms $(i=1,2)$ selling differentiated products. The common discount factor is $\beta=\frac{1}{1.05}$. The state space consists of the level of "know-how" of each firm, $\mathbf{e}=\left(e_{1}, e_{2}\right)$, with know-how observable to all players. ${ }^{6}$ For a firm that is active, $e_{i}=1, \ldots, M$. The BDK model allows for a firm not to be active. An exiting firm is replaced by a potential entrant in state $e_{i}=0$, which lives for a single period if it does not enter. The marginal cost of an active firm $i, c\left(e_{i}\right)$, is $\kappa \rho^{\log _{2}\left(\min \left(e_{i}, m\right)\right)} . \rho \in[0,1]$ is known as the "progress ratio", and a lower number reflects stronger learning economies. When $\rho=1$, marginal costs are $\kappa$ for all $e_{i}$. BDK assume that $m=15$ and $M=30$, which implies that once a firm reaches $m$, additional sales do not lower costs.

Figure 1: Within-Period Timing

\begin{tabular}{ccccc|}
\hline & & & & \\
$\begin{array}{l}\text { a. Active firms } \\
\text { simultaneously }\end{array}$ & b. Buyer & c. Successful & d. Private info. e. State space \\
set prices & purchase & seller's & seller entry & evolves given \\
& experience & cost and scrap & entry/exit \\
& increases & values revealed & choices \\
& by 1 & $\begin{array}{c}\text { and entry/exit } \\
\text { choices made. }\end{array}$
\end{tabular}

Timing, State Transitions and Entry/Exit. Within-period timing is summarized in Figure 1. Active firms simultaneously set prices, and then a buyer, who will be discussed in more detail below, chooses to either buy one unit from one of the active firms or to buy nothing. It is assumed that neither buyers nor sellers can commit to multi-period or multi-unit contracts. The buyer's flow indirect utility when it purchases from active firm $i$ is $v_{i}-p_{i}+\sigma \epsilon_{i}$, where $\epsilon_{i}$ is an iid Type I extreme value payoff shock, $\sigma$ is a scaling parameter that measures the degree of product differentiation and $v_{1}=v_{2}=10$. It is assumed that the no purchase option has $v_{0}-p_{0}=0$.

\footnotetext{
6 Asker, Fershtman, Jeon, and Pakes (forthcoming), Sweeting, Roberts, and Gedge (2020) and Sweeting, Tao, and Yao (2019) consider dynamic models where serially correlated state variables are private information.
} 
When a firm makes a sale its know-how increases by one unit, unless it is already at $M$, in which case it remains at $M$. The firms receive private information draws of entry costs and scrap values, and make simultaneous entry and exit choices. If a firm exits, it cannot re-enter, and it is replaced by a potential entrant in the following period. Entry costs and scrap values are drawn independently from symmetric triangular distributions, with CDFs $F_{\text {enter }}$ and $F_{\text {scrap }}$ and supports $\left[\bar{S}-\Delta_{S}, \bar{S}+\Delta_{S}\right]$, with $\Delta_{S}>0$, and $\left[\bar{X}-\Delta_{X}, \bar{X}+\Delta_{X}\right]$, with $\Delta_{X}>0$, respectively. The fact that the distributions have finite supports implies that when the values of active firms are low enough or high enough, entry or exit will be certain or never optimal. This feature will play a role in our analysis below.

\subsection{Equilibrium without Strategic Buyers.}

The equilibrium concept is symmetric and stationary Markov Perfect equilibrium (MPE, Maskin and Tirole (2001), Ericson and Pakes (1995), Pakes and McGuire (1994)). An equilibrium can be expressed as the solution $\left(p(\mathbf{e})\right.$ (prices), $V^{S}(\mathbf{e})$ (beginning of period seller values), $V^{S, I N T}(\mathbf{e})$ (seller values before entry and exit costs are revealed and continuation choices are made), $\lambda(\mathbf{e})$ (continuation probabilities 7 ) to four sets of equations, with one equation from each set for each state $\left(e_{1}, e_{2}\right)$. Symmetry implies that we can write the equations for firm 1 only.

$\underline{\text { Beginning of period value for firm } 1\left(V_{1}^{S}\right) \text { : }}$

$$
V_{1}^{S}(\mathbf{e})-D_{1}(p(\mathbf{e}), \mathbf{e})\left(p_{1}(\mathbf{e})-c_{1}\left(e_{1}\right)\right)-\sum_{k=0,1,2} D_{k}(p(\mathbf{e}), \mathbf{e}) V_{1}^{S, I N T}\left(\mathbf{e}_{k}^{\prime}\right)=0
$$

where

$$
D_{k}(p, \mathbf{e})=\frac{\exp \left(v_{k}-p_{k}\right)}{\sum_{j=0,1,2} \exp \left(v_{j}-p_{j}\right)}
$$

$\mathbf{e}_{1}^{\prime}=\left(\min \left(e_{1}+1, M\right), e_{2}\right), \mathbf{e}_{2}^{\prime}=\left(e_{1}, \min \left(e_{2}+1, M\right)\right)$ and $\mathbf{e}_{0}^{\prime}=\left(e_{1}, e_{2}\right)$, i.e., the states that the game will transition to if there is a purchase from firm 1 or firm 2, or no purchase, respectively.

\footnotetext{
${ }^{7} \mathrm{BDK}$ use the notation $\phi$ to indicate the probability that a firm does not continue, i.e., it exits or does not enter. Therefore, to match their notation, replace $\lambda$ with $1-\phi$.
} 
$\underline{\text { Value for firm } 1 \text { before entry/exit stage }\left(V_{1}^{S, I N T}\right) \text { : }}$

$$
V_{1}^{S, I N T}(\mathbf{e})-\left(\begin{array}{c}
\beta \lambda_{1}(\mathbf{e}) \lambda_{2}(\mathbf{e}) V_{1}^{S}(\mathbf{e})+\beta \lambda_{1}(\mathbf{e})\left(1-\lambda_{2}(\mathbf{e})\right) V_{1}^{S}\left(e_{1}, 0\right)+ \\
\left(1-\lambda_{1}(\mathbf{e})\right) E\left(X \mid \lambda_{1}(\mathbf{e})\right)
\end{array}\right)=0
$$

for $\mathbf{e}=\left(e_{1}, e_{2}\right)$ where $e_{1}, e_{2}>0$, with similar equations when one or both firms is a potential entrant. $E\left(X \mid \lambda_{1}(\mathbf{e})\right)$ is the expected scrap value when firm 1 chooses to exit.

First-order condition for firm 1's price $\left(p_{1}\right)$ if $e_{1}>0$ :

$$
D_{1}(p(\mathbf{e}), \mathbf{e})+\sum_{k=0,1,2} \frac{\partial D_{k}(p(\mathbf{e}), \mathbf{e})}{\partial p_{1}} V_{1}^{S, I N T}\left(\mathbf{e}_{k}^{\prime}\right)+\left(p_{1}(\mathbf{e})-c_{1}\left(e_{1}\right)\right) \frac{\partial D_{1}(p(\mathbf{e}), \mathbf{e})}{\partial p_{1}}=0
$$

Firm 1's continuation probability in entry/exit stage $\left(\lambda_{1}\right)$ :

$$
\begin{gathered}
\lambda_{1}(\mathbf{e})-F_{\text {enter }}\left(\beta\left[\lambda_{2}(\mathbf{e}) V_{1}\left(1, e_{2}\right)+\left(1-\lambda_{2}(\mathbf{e})\right) V_{1}(1,0)\right]\right)=0 \text { if } e_{1}=0 \\
\lambda_{1}(\mathbf{e})-F_{\text {scrap }}\left(\beta\left[\lambda_{2}(\mathbf{e}) V_{1}\left(e_{1}, \max \left(1, e_{2}\right)\right)+\left(1-\lambda_{2}(\mathbf{e})\right) V_{1}\left(e_{1}, 0\right)\right]\right)=0 \text { if } e_{1}>0
\end{gathered}
$$

Multiple equilibria exist when there is more than one set of values, prices and continuation probabilities that satisfy these equations.

\subsection{Equilibrium with Strategic Buyers.}

We now explain how we extend the BDK model to allow for strategic buyers. Suppose that there is a pool of $\frac{1}{b^{p}}$ symmetric buyers (e.g., 10 buyers if $b^{p}=0.1$ ). Buyers' discount factors are $\beta^{b}$, although we will assume $\beta^{b}=\beta$ except to highlight an important difference between $b^{p}$ and buyer patience. One member of the pool is chosen to be the buyer in each period, and the chosen buyer returns to the pool at the end of the period. The flow utility of the chosen buyer is the same as was assumed for non-strategic buyers, with buyer preferences iid across periods and sellers. In particular, a buyer's preferences do not depend on that buyer's own past consumption choices. However, a buyer will recognize that its purchase choice affects how the state of the model may evolve.

The beginning of period buyer value $\left(V^{B}\right)$ is defined before nature has chosen the buyer for the current period. To define this value it is useful to first define $V^{B, I N T}$, the value of a 
buyer (whether or not they made the purchase choice this period) after the purchase decision has been made and seller know-how has evolved, but before entry and exit choices are made. $\underline{\text { Value for buyer before entry/exit stage }\left(V^{B, I N T}\right) \text { : }}$

$$
V^{B, I N T}(\mathbf{e})-\beta^{b}\left(\begin{array}{c}
I\left(e_{1}>0, e_{2}>0\right) \lambda_{1}(\mathbf{e}) \lambda_{2}(\mathbf{e}) V^{B}(\mathbf{e})+\ldots \\
I\left(e_{1}=0, e_{2}>0\right) \lambda_{1}(\mathbf{e}) \lambda_{2}(\mathbf{e}) V^{B}\left(1, e_{2}\right)+\ldots \\
I\left(e_{1}>0, e_{2}=0\right) \lambda_{1}(\mathbf{e}) \lambda_{2}(\mathbf{e}) V^{B}\left(e_{1}, 1\right)+\ldots \\
I\left(e_{1}=0, e_{2}=0\right) \lambda_{1}(\mathbf{e}) \lambda_{2}(\mathbf{e}) V^{B}(1,1)+\ldots \\
I\left(e_{1}>0, e_{2}>0\right) \lambda_{1}(\mathbf{e})\left(1-\lambda_{2}(\mathbf{e})\right) V^{B}\left(e_{1}, 0\right)+\ldots \\
\ldots
\end{array}\right)=0
$$

where the sum is over the states that the game may transition to given entry/exit choices. Seller symmetry implies that $V^{B, I N T}\left(e_{1}, e_{2}\right)=V^{B, I N T}\left(e_{2}, e_{1}\right)$ and $V^{B}\left(e_{1}, e_{2}\right)=V^{B}\left(e_{2}, e_{1}\right)$.

Given the definition of $V^{B, I N T}$, the probability that a buyer chooses seller $i=1,2$ is

$$
D_{i}(p, \mathbf{e})=\frac{\exp \left(v_{i}-p_{i}+V^{B, I N T}\left(\mathbf{e}_{i}^{\prime}\right)\right)}{\sum_{k=0,1,2} \exp \left(v_{k}-p_{k}+V^{B, I N T}\left(\mathbf{e}_{k}^{\prime}\right)\right)} .
$$

with a similar formula for the outside option. $V^{B}$ is then defined as $\underline{\text { Beginning of Period Buyer Value }\left(V^{B}\right) \text { : }}$

$V^{B}(\mathbf{e})-b^{p} \log \left(\sum_{k=0,1,2} \exp \left(v_{k}-p_{k}+V^{B, I N T}\left(\mathbf{e}_{k}^{\prime}\right)\right)\right)-\left(1-b^{p}\right) \sum_{k=0,1,2} D_{k}(p(\mathbf{e}), \mathbf{e}) V^{B, I N T}\left(\mathbf{e}_{k}^{\prime}\right)=0$

where $b^{p}$ is the probability that a buyer in the pool is the chosen buyer in the current period, in which case its value reflects the current and future surplus of its purchase choice. The value of a buyer that is not chosen is the weighted sum of the $V^{B, I N T} \mathrm{~s}$, with the weights reflecting the probability that the chosen buyer makes different purchase choices.

Discussion. The model is equivalent to the original BDK model if $b^{p}=0$, with $V^{B}=$ $V^{B, I N T}=0$. If $b^{p}=1$, there is a monopsonist who can buy one unit every period. Our presentation assumed that $b^{p}$ takes on values where $\frac{1}{b^{p}}$ is an integer. However, $b^{p}$ is also equal 
to the share of discounted future buyer surplus that a buyer expects to receive and, if we have a behavioral interpretation of the parameter, we can also consider values of $b^{p}>0.5$ or values where $\frac{1}{b^{p}}$ is not an integer, which will be a natural interpretation when we change $b^{p}$ continuously.

We will illustrate that one should not interpret variation in $b^{p}$ as variation in buyer patience ${ }^{8}$ Even though equilibrium seller behavior will be the same when $b^{p}=0$ or buyers are myopic $\left(\beta^{b}=0\right)$, an increase in $\beta^{b}$ changes the relative weight that a buyer places on surplus in future periods in a way that an increase in $b^{p}$ does not.

\subsection{Methods for Finding Equilibria and their Classification}

BDK and BDKS use two computational approaches to find equilibria. The first approach follows Pakes and McGuire (1994) who use an iterative algorithm, where optimal prices/continuation probabilities are computed and values are updated in each step, to find an equilibrium. Their second approach uses homotopies, which are essentially applications of the implicit function theorem to the system of equations that define an equilibrium, to trace equilibrium correspondences through the strategy and value space as a single parameter is varied, starting from an equilibrium found by the Pakes-McGuire algorithm or a different homotopy. An " $\alpha$ homotopy" is a homotopy where the equilibrium is traced varying parameter $\alpha$. An advantage of the homotopy approach is that it can identify equilibria that, because of the failure of local stability conditions, cannot be found using the Pakes-McGuire algorithm unless one started exactly at the equilibrium. However, even when the homotopy approach is applied repeatedly and different parameters are varied, it is not guaranteed to find all equilibria.9 Therefore, if homotopies find only one equilibrium for given parameters, it is unclear how confidently a researcher should claim that the equilibrium is unique.

In this paper we also make use of the homotopy approach, with our implementation detailed in Appendix A 10 However, we also use an additional approach that can prove whether

\footnotetext{
${ }^{8}$ A question from David Besanko made us realize that a patience interpretation was inappropriate.

${ }^{9}$ For example, BDK1, page 880: "Although it cannot be guaranteed to find all equilibria, the advantage of this method is its ability to explore the equilibrium correspondence and search for multiple equilibria in a systematic fashion."

${ }^{10}$ Some of our numerical choices (e.g., tolerances) may differ from those of BDK or BDKS, but our results are almost identical when $b^{p}=0$.
} 
particular types of equilibrium exist, as it helps to support our claims that equilibria are unique. In particular, we consider the following two types of equilibria.

Definition An equilibrium is accommodative if $\lambda_{1}\left(e_{1}, e_{2}\right)=\lambda_{2}\left(e_{1}, e_{2}\right)=1$ for all states $\left(e_{1}, e_{2}\right)$ where $e_{1}>0$ and $e_{2}>0$.

Definition An equilibrium has the "Some Exit Leads to Permanent Monopoly" (SELPM) property if there is some $\mathbf{e}=\left(e_{1}, e_{2}\right)$ where $e_{1}>e_{2}>0$, and (i) $\lambda_{2}(\mathbf{e})<1$, (ii) $\lambda_{2}\left(e_{1}^{\prime}, 0\right)=0$ and $\lambda_{1}\left(e_{1}^{\prime}, 0\right)=1$ for all $e_{1}^{\prime} \geq e_{1}$, and (iii) $\lambda_{1}\left(e_{1}^{\prime}, e_{2}^{\prime}\right)=1$ for all $e_{1}^{\prime} \geq e_{1}, e_{2}^{\prime} \geq e_{2}$.

BDK2 define accommodative equilibria in the same way. In these equilibria a game starting at state $(1,1)$ must end up at $(M, M)$, and then stay in that state, with both firms at the bottom of their cost curves. Equivalently, the ergodic distribution consists only of $(M, M)$. It is straightforward to check if an accommodative equilibrium exists by solving for equilibrium prices assuming no exit, and then verifying that no exit is optimal. As described in Appendix $\mathrm{B}$, by examining the best response price functions in each state, we are confident that at most one accommodative equilibrium can exist.

Our definition of SELPM equilibria is new. The key feature of a SELPM equilibrium is that from the duopoly state e the game either will transition to permanent monopoly, following exit, in which case it will end up in states $(M, 0)$ or $(0, M)$, which will be absorbing, or will remain in permanent duopoly, with $(M, M)$ as an absorbing state. In lower know-how states, exit and re-entry is possible. Appendix B describes an algorithm that will be able to identify a state $\mathbf{e}$, if one exists, as long as we are able to solve for all equilibria in a given state for a given set of buyer and seller continuation values if the state was to change 11 An extended version of this algorithm can also be used to identify the existence of equilibria where any exit in the game will lead to permanent monopoly (AELPM) (the formal definition of an AELPM equilibrium is provided in Appendix B). All AELPM equilibria are SELPM.

It is straightforward to check whether an equilibrium found by a homotopy is accommodative or SELPM. For the parameters that we consider, all of the equilibria that we identify in

\footnotetext{
${ }^{11}$ Our algorithm follow paths consistent with the definition of a SELPM equilibrium, starting in the absorbing states, until we find a state e or determine that no such state exists. This does not involve solving for equilibrium strategies in the whole game, so it does not provide a method for counting the number of SELPM equilibrium. The structure of the game implies that there will always be positive probability of reaching $\mathbf{e}$ if the game starts in state $(1,1)$ and that equilibrium strategies for lower know-how states that are consistent with the existence of state $\mathbf{e}$ will exist.
} 
the extended BDK model are either accommodative or SELPM as long as exit is never optimal in state $(M, M)$ (i.e., when both firms are at the bottom of their learning curves). ${ }^{12}$ Therefore when we find that, for particular parameters, an accommodative equilibrium exists and no SELPM equilibria exist, without relying on homotopies, this provides fairly convincing, and new, evidence that the accommodative equilibrium is likely to be the only equilibrium in the full game 13 One might also argue that policy analysis should be particularly concerned with equilibria where permanent monopoly could be established.

\section{The Effects of Strategic Buyers in the Extended BDK Model: An Illustration}

In this section, we examine what happens if we vary $b^{p}$ when $\sigma=1$ and $\rho=0.75$ ("the illustrative parameters") ${ }^{14}$ BDK1 argue that these parameters are empirically plausible even though they are not intended to represent any particular industry. We assume $\beta^{b}=\beta=\frac{1}{1.05}$ unless otherwise noted.

\subsection{Three Baseline Equilibria for $b^{p}=0$}

There are three equilibria that can be supported for these parameters. Table 1 reports the strategies for a subset of states. The three equilibria differ only in strategies where one or both firms have not made a sale, i.e., where at least one $e$ is equal to 0 or 1 . Two of the equilibria involve some positive probability of exit by a firm with $e_{i}=1$, and they involve low equilibrium prices in these states. Intuitively, when a rival that has not made a sale may exit, a firm has an incentive to set a low price to make sure that the rival does not make a sale,

\footnotetext{
${ }^{12}$ If scrap values can be very high and marginal costs in state $M$ are high enough (i.e., there is little learningby-doing), there will be some possibility of exit in state $(M, M)$. The assumption that scrap values are drawn from a triangular distribution with limited support is therefore important. If we considered parameters where entry costs could be very low, re-entry might always be optimal and there would never be permanent monopoly. Some non-accommodative equilibria would therefore not be SELPM if we considered a broader set of parameters.

${ }^{13}$ Of course, we are not claiming to be first in using a recursive algorithm to prove the properties of equilibria in a dynamic model with LBD. Cabral and Riordan (1994) and BDKS use backwards induction to prove uniqueness when there is no possibility of exit and no forgetting respectively. However, our use of this type of algorithm to prove whether or not a particular type of equilibrium with exit exists, is, we believe, new.

${ }^{14}$ For the remaining parameters: $\kappa$ (cost the top of the learning curve) is $10, \bar{X}$ (scrap value) has a symmetric triangular distribution on $[0,3], \bar{S}$ (entry cost) has a symmetric triangular distribution on $[3,6]$.
} 


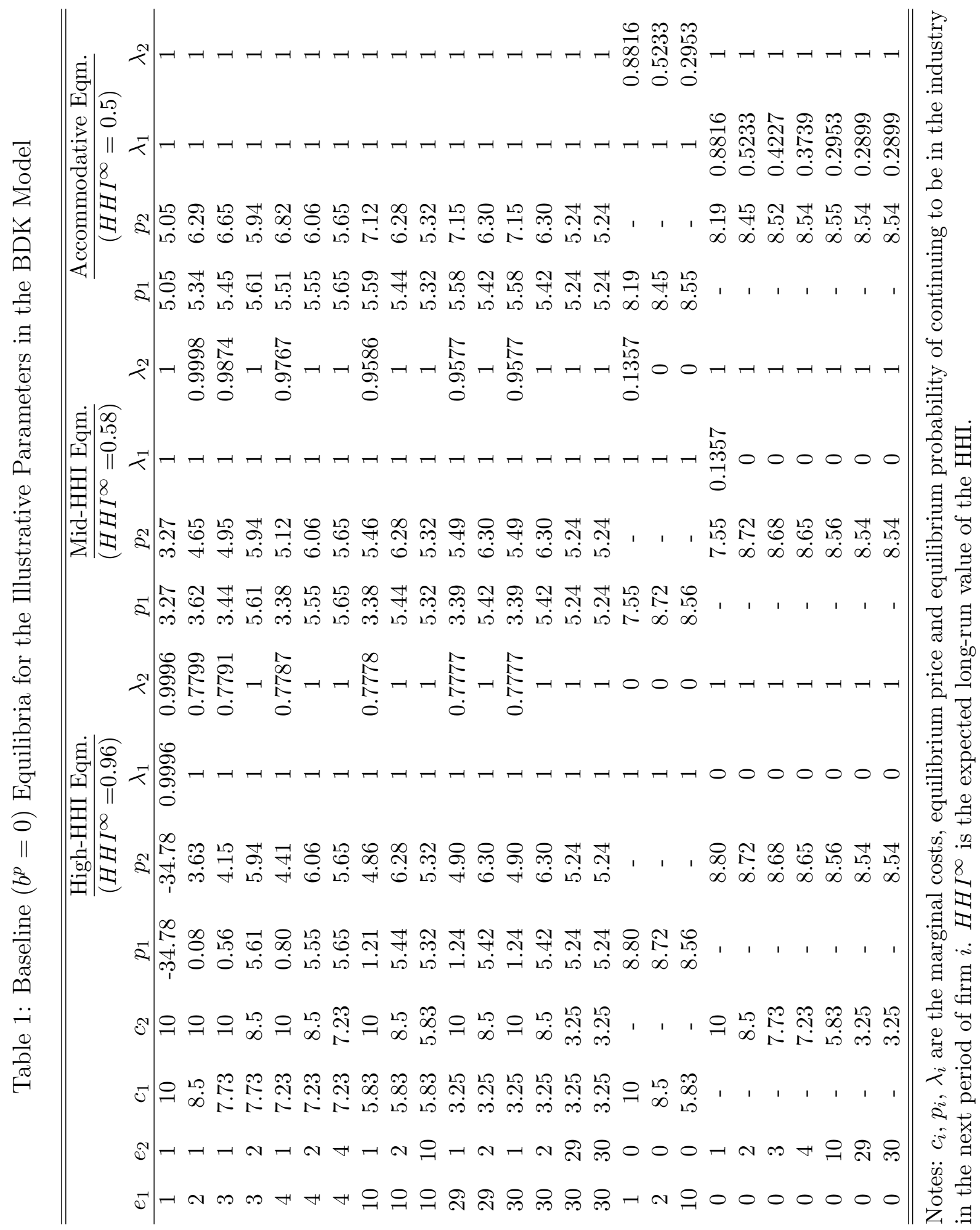


and, in turn, this can make exit more attractive.

Long-run outcomes can be measured by the expected long-run HHI $\left(H H I^{\infty}\right)$ implied by firm strategies assuming that the game begins in state $(1,1)$. BDK define $H H I^{\infty}[5$ as

$$
H H I^{\infty}=\sum_{\mathbf{e} \geq(0,0)} \frac{\mu^{\infty}(\mathbf{e})}{1-\mu^{\infty}(0,0)} H H I(\mathbf{e}) \text { where } H H I(\mathbf{e})=\sum_{i=1,2}\left(\frac{D_{i}(p, \mathbf{e})}{D_{1}(p, \mathbf{e})+D_{2}(p, \mathbf{e})}\right)^{2}
$$

and $\mu^{\infty}(\mathbf{e})$ is the probability that the game is in state $\mathbf{e}$ in the ergodic distribution. The long-run expected average price $\left(P^{\infty}\right)$ can be defined in a similar way.

In any accommodative equilibrium, the ergodic distribution contains only state $(M, M)$ so $H H I^{\infty}=0.5$ and $P^{\infty}=5.24$. The other equilibria are SELPM, so the ergodic distributions contain states $(M, M),(M, 0)$ and $(0, M)$ only, and $H H I^{\infty}$ and $P^{\infty}$ depend only on the probabilities of these states in each equilibrium, as equilibrium prices in absorbing states do not depend on $b^{p}$ (the optimal buyer strategy is to act statically). The Mid-HHI equilibrium is AELPM, as only a laggard exits and there is no re-entry against an incumbent ${ }^{16}$

\subsection{Equilibrium Outcomes as $b^{p}$ Varies}

Figure 2 shows the values of $H H I^{\infty}$ and $P^{\infty}$ implied by the equilibria on the $b^{p}$-homotopy paths from each of the baseline equilibria. The High- and Mid-HHI baseline equilibria lie at two ends of a single path that does not extend beyond $b^{p}=0.142$. All of the equilibria on this path are SELPM. On the other hand, the equilibria on the path from the accommodative baseline equilibrium are all accommodative.

As noted above, one might wonder if there are additional equilibria with exit on disconnected sections of the equilibrium correspondence. We use our recursive algorithm to test for the existence of SELPM equilibria when we increase $b^{p}$ from 0 to 1 in steps of 0.01 . We find that no SELPM equilibria exist for $b^{p} \geq 0.15$, consistent with the homotopies identifying all equilibria.

Figure 3 shows what the equilibria on the homotopy paths imply for the net present values of consumer and total surplus, for games starting in $(1,1){ }^{17}$ The net present values are

\footnotetext{
${ }^{15}$ In practice, BDK1 calculate $H H I^{\infty}$ based on the probability distribution of states after 1,000 periods (see BDK1, p. 883). We use the actual limiting distribution.

${ }^{16}$ The High-HHI equilibrium is not AELPM, as there is a small probability that both firms exit in $(1,1)$.

${ }^{17} \mathrm{BDK} 1$ calculate welfare assuming that the game starts in state $(1,1)$, whereas BDK2 calculate welfare
} 
Figure 2: Extended BDK Model: Equilibrium Expected Long-Run HHI and Price as a Function of $b^{p}$ for the Illustrative Parameters. The black line traces the homotopy path from the Accommodative (A) baseline equilibrium. The red line traces the overlapping paths from the High-HHI (H) and Mid-HHI (M) baseline equilibria.

(a) Expected Long-Run HHI $\left(H H I^{\infty}\right)$.

(b) Expected Long-Run Prices $\left(p^{\infty}\right)$
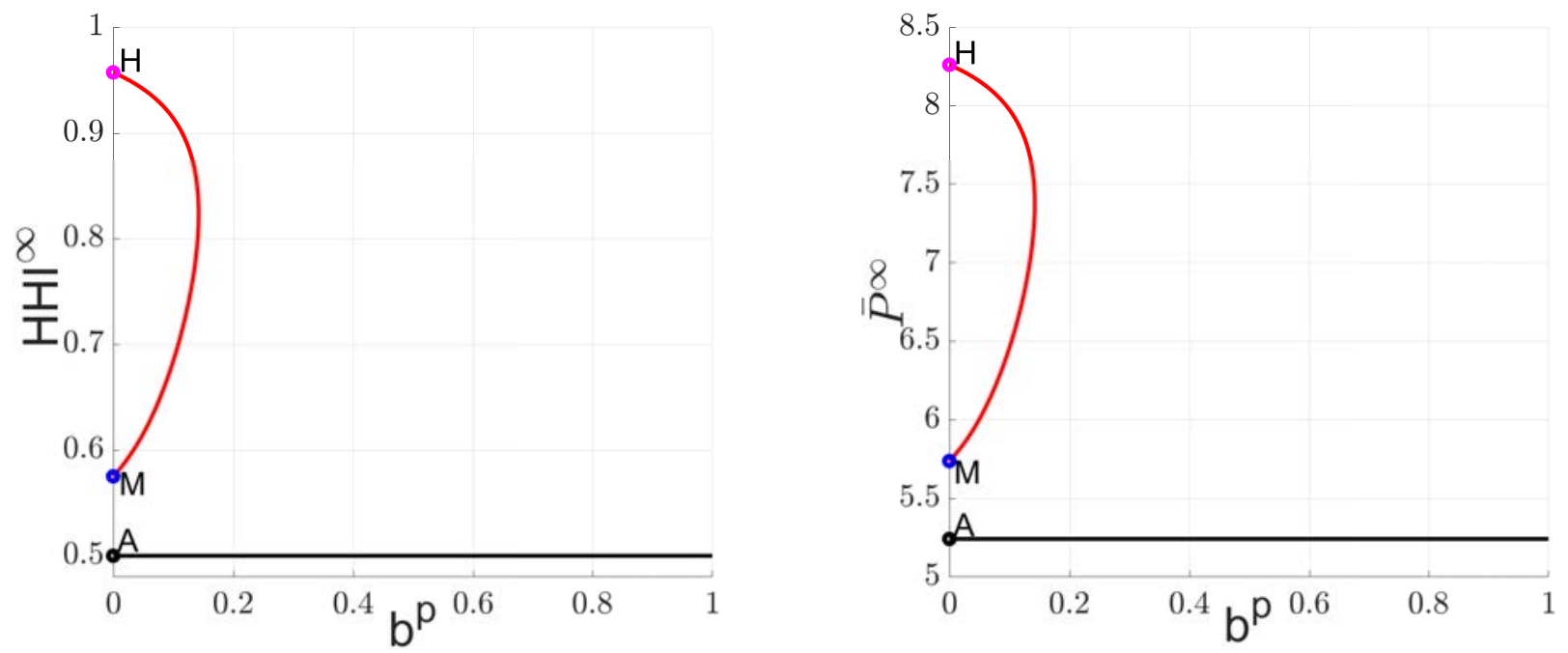

Figure 3: Extended BDK Model: Equilibrium Expected NPV of Welfare as a Function of $b^{p}$ for the Illustrative Parameters. The black line traces the homotopy path from the Accommodative (A) baseline equilibrium. The red line traces the overlapping paths from the High-HHI $(\mathrm{H})$ and Mid-HHI (M) baseline equilibria.

(a) Total Surplus

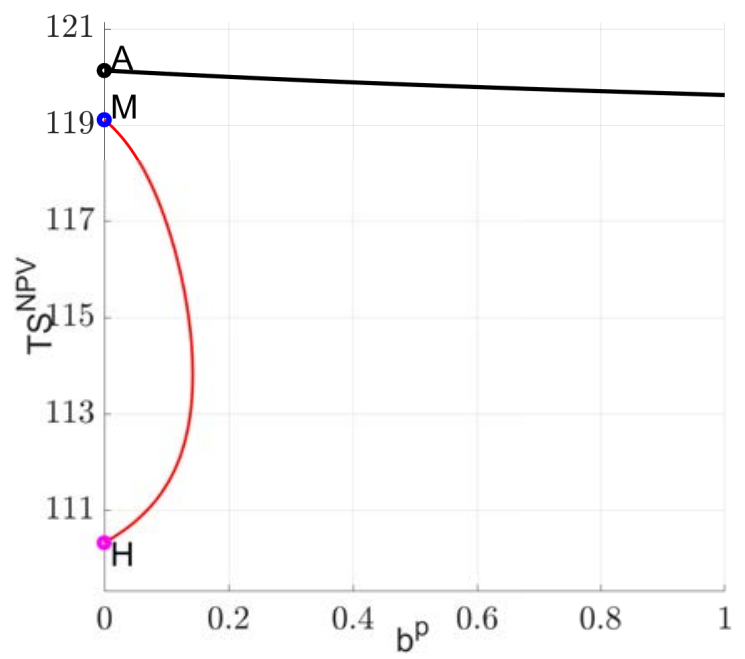

(b) Consumer Surplus

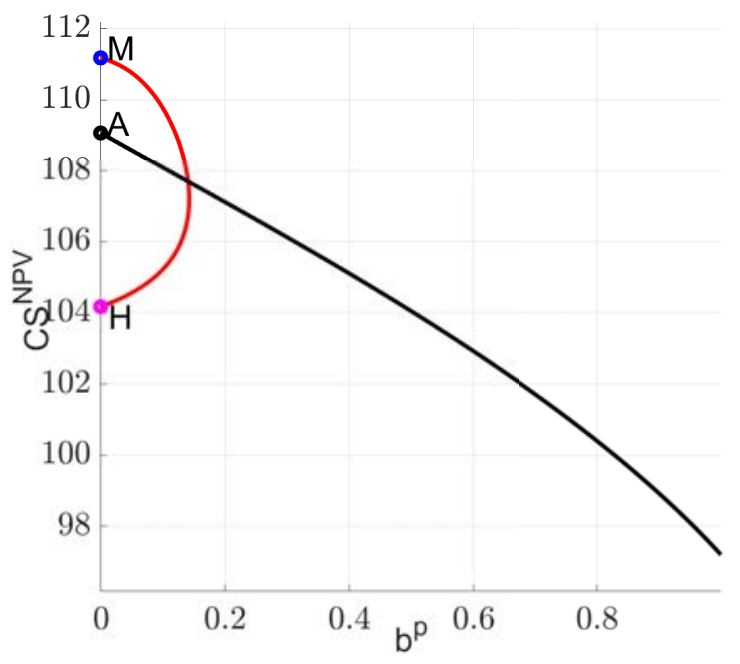


affected both by long-run variety and prices (better in accommodative equilibria) but also the intensity of competition to gain an advantage in the initial periods of the game. Total surplus is highest in the accommodative equilibria. On the other hand, consumer surplus is maximized in the baseline Mid-HHI equilibrium, although it is lowest in the High-HHI equilibrium, where monopoly is likely to be quickly established. Therefore, the type of equilibrium that tends to exist when buyers act strategically is not necessarily the best equilibrium for buyers. We will see that initial prices in an accommodative equilibrium tend to increase with $b^{p}$, causing both measures of surplus to fall.

Appendix C.1 explores the welfare patterns by examining what happens to the number of sales and production costs, in the long-run and in the first ten periods of the game. Even though one firm is likely to exit, surplus is highest in the High-HHI equilibrium in the first ten periods because duopoly prices are so low.

\subsection{Effect of Changes in $b^{p}$ on Equilibrium Strategies and Dynamic Incentives}

To explain these changes in the existence of different types of equilibria, outcomes and welfare, we focus on what happens in a single state, $(3,1)$. In the SELPM baseline equilibria, if firm 2 makes the sale in this state, there will be permanent duopoly, and future play will be the same as in the accommodative equilibrium, whereas if firm 1 makes the sale or no sale occurs, firm 2 may exit and monopoly may result. A buyer in this state can therefore play a pivotal role in how the market develops, i.e., there is some probability that the long-run outcome will be duopoly only if it buys from firm 2 . In an accommodative equilibrium, the buyer can make the firms more symmetric by buying from firm 2, but cannot affect long-run market structure.

Figure 4(a) shows how the demand for firm 1 (the leader) changes with $b^{p}$ when we hold seller pricing and exit strategies (in all states) fixed at their baseline $b^{p}=0$ equilibrium values, so that the changes in demand simply reflect the incentives of a buyer to affect how the game evolves ${ }^{18}$ We see that the probability of purchasing from firm 1 falls as $b^{p}$ rises in all of the

assuming the game starts in state $(0,0)$, so that initial entry costs are included and the possibility that there is never duopoly is accounted for. While both measures are interesting, we focus on NPV measures assuming that the game starts in $(1,1)$ as antitrust analysis is typically focused on settings where there is actual competition during the initial stages of an industry's development.

${ }^{18}$ When we vary $p_{1}$, the players assume that $p_{1}$ will have its baseline equilibrium value if the game is in state $(3,1)$ in any future period. $p_{2}$ is held fixed at its baseline equilibrium value. 


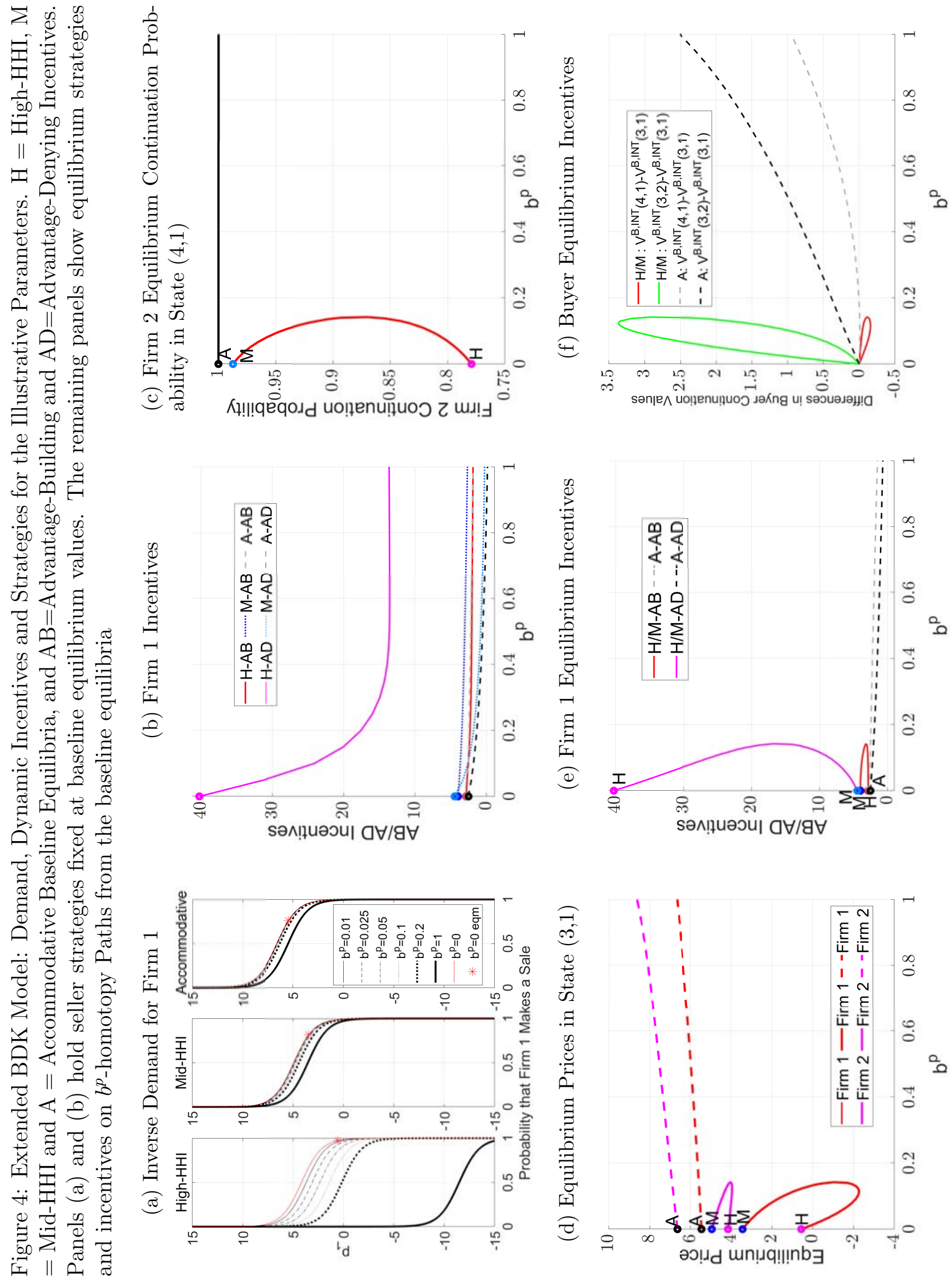


equilibria, but that the falls are especially dramatic in the High-HHI equilibrium, even for low values of $b^{p}$. For example, the probability that firm 1 makes the sale falls from 0.973 to 0.695 as $b^{p}$ increases from 0 to 0.1 .

To understand how shifts in demand in future states affects a seller's dynamic incentives, we follow BDK in defining two components of a seller's continuation values in a particular state.

Definition The advantage-building incentive for firm 1 is $V_{1}^{S, I N T}\left(e_{1}+1, e_{2}\right)-V_{1}^{S, I N T}\left(e_{1}, e_{2}\right)$. The advantage-denying incentive for firm 1 is $V_{1}^{S, I N T}\left(e_{1}, e_{2}\right)-V_{1}^{S, I N T}\left(e_{1}, e_{2}+1\right)$.

The advantage-building incentive therefore measures the increase in a firm's continuation value when it makes a sale, compared to neither firm making a sale. The advantage-denying incentive measures the increase in the continuation value from no sale compared to the rival making a sale. BDK1 show that the advantage-denying incentive is important in sustaining equilibria with exit or high values of $H H I^{\infty} 19$

Figure 4(b) shows these dynamic incentives for firm 1 in state $(3,1)$ as a function of $b^{p}$ holding seller strategies fixed at their baseline equilibrium values, so that changes reflect only how buyer behavior affects the evolution of the game. Even though firm 2's exit probabilities are not changing, the advantage-denying incentive in the High-HHI equilibrium falls rapidly with $b^{p}$, reflecting how a strategic buyer is more likely to buy from firm 2 , if it does not exit, in future periods. The other incentives, which are much smaller, decline only slightly, and more linearly, as $b^{p}$ rises.

The remaining parts of the figure examine how equilibrium strategies and dynamic incentives change (i.e., when we allow for both buyer and seller strategies to adjust) along the $b^{p}$ homotopy paths from the baseline equilibria. Figure 4(c) shows the probability that firm 2 will continue in state $(4,1)$, i.e., the probabilities associated with firm 2's exit choice when firm 1 makes the sale in state $(3,1)$. Figure $4(\mathrm{~d})$ shows the equilibrium prices of both firms in state $(3,1)$. Figure 4(e) shows the equilibrium advantage-building and denying incentives for firm 1. As $b^{p}$ increases from zero, firm 1's equilibrium price initially falls sharply when we follow the path from the High-HHI equilibrium. As the advantage-denying incentive is declining,

\footnotetext{
${ }^{19}$ See, for example, Figure 3 (middle panel) in BDK1 where the surviving equilibria are accommodative when the advantage-denying incentive (Definition 2) is removed.
} 
partly because firm 2 is less likely to exit, and the advantage-building incentive is almost flat, the fall in price reflects the decline in demand in state $(3,1)$ as a strategic buyer becomes more likely to buy from firm 2. When the advantage-denying incentive is small enough, the incentive to maintain a price that is significantly below marginal cost disappears, and this type of equilibrium can no longer be sustained.

Figure 4 (f) shows the equilibrium dynamic incentives of a strategic buyer, measured by the change in the chosen buyer's continuation values when, compared to not buying, it buys from

firm $1\left(V^{B, I N T}(4,1)-V^{B, I N T}(3,1)\right)$ or firm $2\left(V^{B, I N T}(3,2)-V^{B, I N T}(3,1)\right)$. These incentives are zero in all of the equilibria when $b^{p}=0$. On the other hand, as $b^{p}$ rises, the dynamic incentive to buy from firm 2 increases sharply in the non-accommodative equilibria, while there is a a dynamic disincentive to buy from firm 1. In an accommodative equilibrium there is a positive dynamic incentive to buy from either firm as this lowers future costs and prices, although the incentive to buy from firm 2 is greater. The positive dynamic incentives, which raises demand for both firms, explains why equilibrium prices increase on the path from the accommodative baseline equilibrium.

\subsection{Comparison to Variation in Buyer Discount Factor}

One might expect that an increase in $b^{p}$ would have a similar effect on equilibrium outcomes to making a monopsonist buyer more patient (i.e., increasing $\beta^{b}$ when $b^{p}=1$ ). Increasing either $b^{p}$ or $\beta^{b}$ causes buyers to place more weight on future surplus, but changes in $\beta^{b}$ also affect the relative weight placed on surplus in different future periods. As a result, changes in $\beta^{b}$ and $b^{p}$ can affect what happens in different ways, even though equilibrium strategies when $\beta^{b}=0$ or $b^{p}=0$ are identical.

We can illustrate this difference using our state $(3,1)$ example. In the High-HHI equilibrium, firm 1's price in state $(4,1)$ is even lower than its price in state $(3,1)$. Therefore when $\beta^{b}$ increases from zero, a monopsonist buyer may actually shift its demand towards firm 1 even though this increases the probability of long-run monopoly. This is illustrated in Figure 5(a), which can be compared to Figure 4 (a) as seller strategies are the same in both cases. Using High-HHI or Mid-HHI seller strategies, demand for firm 1 is higher when $\beta^{b}=0.7$ than when $\beta^{b}=0$. In contrast, demand was lower for firm 1 for all $b^{p}>0$. This type of demand shift 
Figure 5: Extended BDK Model: Inverse Demand Curves For Seller 1 in State $(3,1)$ and Equilibrium Expected Long-Run HHI as a Function of $\beta^{b}\left(b^{p}=1\right)$ for the Illustrative Parameters. In panel (a) seller strategies are held at baseline equilibrium levels. The paths in panel (b) are traced by $\beta^{b}$-homotopies.

\section{(a) Inverse Demand for Firm 1}

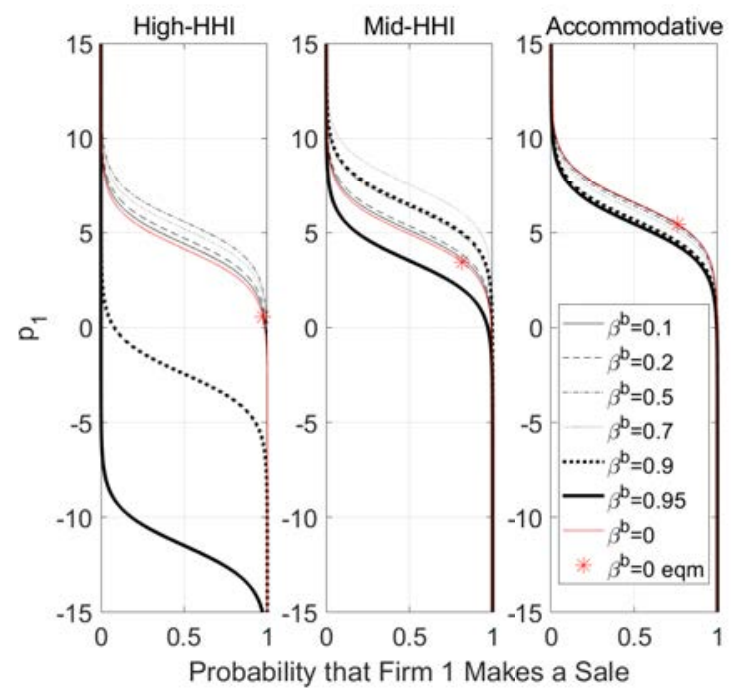

(b) Equilibrium $H H I^{\infty}$

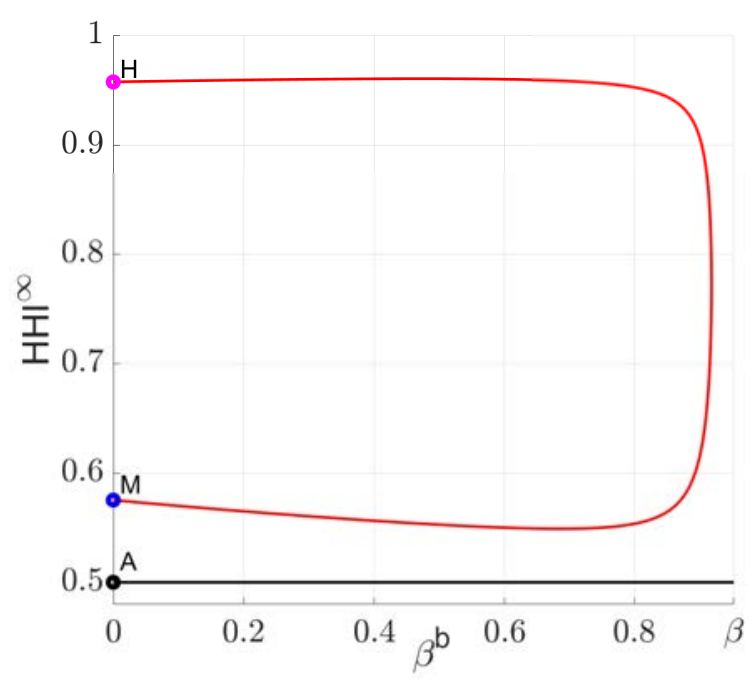

implies that the equilibrium dynamic incentive for a seller to set a low price may increase when $b^{p}$ increases 20

Figure $5(\mathrm{~b})$ shows the $H H I^{\infty}$ values implied by the equilibria traced by $\beta^{b}$-homotopies from the baseline equilibria. Non-accommodative equilibria exist until $\beta^{b}$ is almost equal to $\beta$, in contrast to how multiplicity is eliminated for quite low $b^{p}$.

We assume that $\beta^{b}=\beta$ and we will vary $b^{p}$ in the rest of this paper. This is because we think of industries with LBD as typically having a number of long-lived buyers, each of whom accounts for only a share of current and future demand, but who may care about the future just as much as the sellers. This situation is more closely approximated by a model where $\beta^{b}=\beta$ and $b^{p}>0$.

\section{Results for the Extended BDK Model Across Values of $\rho$ and $\sigma$}

We now examine what happens when we look across values of $\rho$, the progress ratio, which determines the extent of LBD, and $\sigma$, which measures the degree of product differentiation,

\footnotetext{
${ }^{20}$ In fact, when we calculate the advantage-denying incentives for firm 1 , with fixed seller strategies, it increases until $\beta^{b}$ is 0.8 for the Mid-HHI equilibrium and until $\beta^{b}$ is 0.7 for the High-HHI equilibrium.
} 
Figure 6: Extended BDK Model: Equilibrium Expected Long-Run HHI $\left(H H I^{\infty}\right)$ on $\sigma$ Homotopy Paths for Different $b^{p}$, with Other Parameters at their Illustrative Values.

(a) $b^{p}=0$

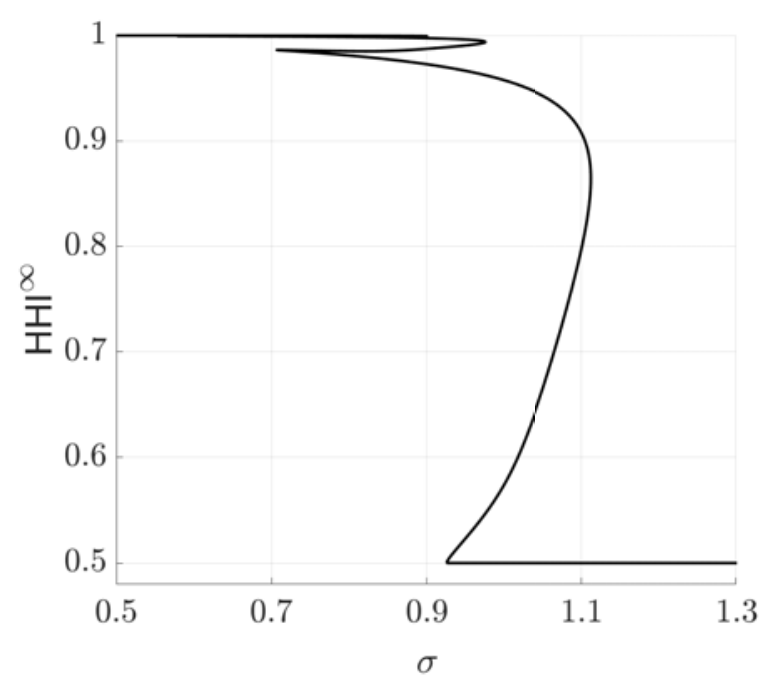

(b) Full Range of $b^{p}$

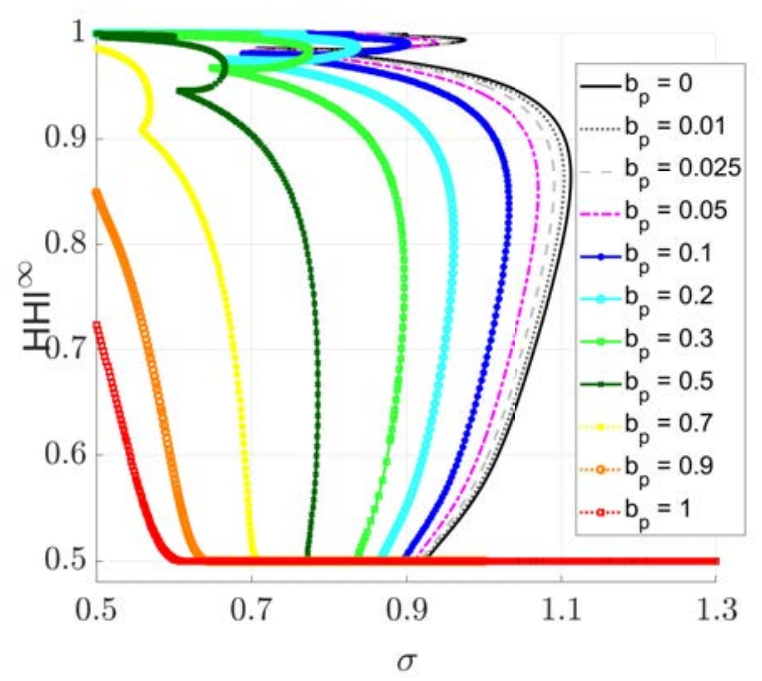

with other parameters fixed at their illustrative values. When product differentiation falls, equilibrium duopoly profits tend to shrink, which tends to lead to more exit. When $\rho$ falls, there are two effects. First, lower costs tend to increase duopoly profits, making exit less attractive. On the other hand, a firm that makes initial sales gains a larger cost advantage, which may increase the probability that the laggard exits.

\subsection{Long-Run Market Structure and Multiplicity of Equilibria}

Figure 6(a) (which matches BDK1 Figure 2, Panel B) shows the $H H I^{\infty}$ implied by the equilibria on the $\sigma$-homotopy path when $b^{p}=0$ and $\rho=0.75$ 21 The other parameters are held at their illustrative values. When $\sigma>1.12$ (high differentiation), there is only an accommodative equilibrium $\left(H H I^{\infty}=0.5\right)$, but otherwise at least one equilibrium exists where a firm may exit and the market can end up as a permanent monopoly. For $\sigma<0.9$, all of the equilibria have a high probability of monopoly ( $H H I^{\infty}$ very close to 1 ), and, as a result of the homotopy path bending back on itself (in a way that cannot be seen in the figure), there can be many equilibria. For example, for $\sigma=0.8$ there are 23 equilibria, all with $H H I^{\infty} \geq 0.952^{22}$ All of the equilibria computed with $H H I^{\infty}>0.5$ are SELPM.

Figure 6(b) shows that, as $b^{p}$ increases, the $\sigma$-homotopy paths unwind, reducing multiplic-

\footnotetext{
${ }^{21}$ The path begins at $\sigma=1.3$ where we find the equilibrium by solving the equilibrium equations.

${ }^{22}$ Prices are identical in all of these equilibria for $\left(e_{1}>6, e_{2}>6\right)$ because there is no exit in these states.
} 
Figure 7: Extended BDK Model: Equilibrium Expected Long-Run HHI $\left(H H I^{\infty}\right)$ on $\rho$ Homotopy Paths for Different $b^{p}$, with Other Parameters at their Illustrative Values. Panel (b) classifies the equilibria into accommodative, AELPM and non-AELPM SELPM types, distinguishing within the latter two groups based on whether the equilibrium satisfies BDK2's definition of an aggressive equilibrium.

(a) Full Range of $b^{p}$

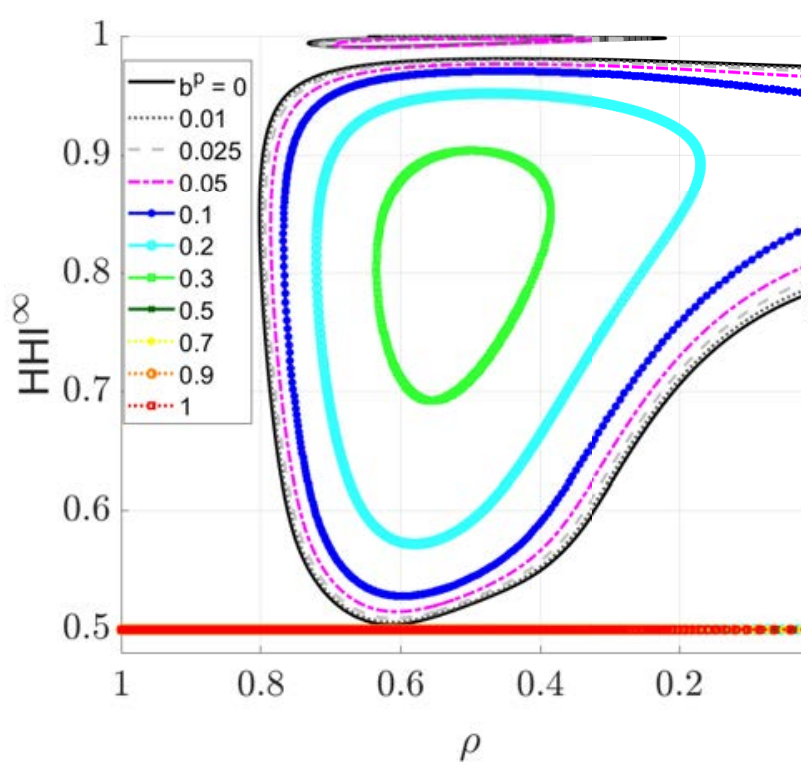

(b) Classification

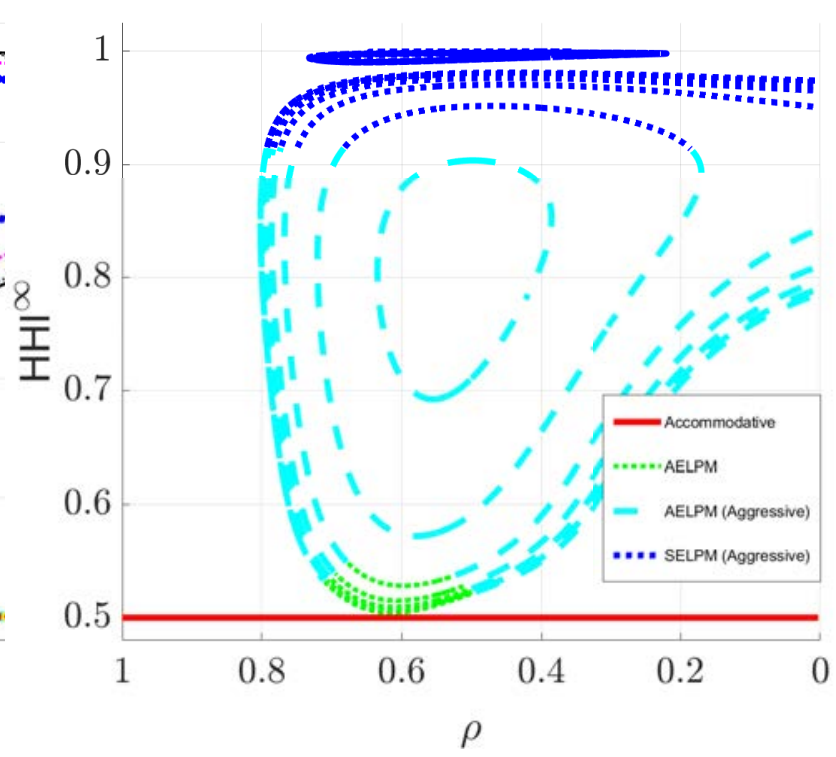

ity. Accommodative equilibria can be supported for lower $\sigma$. When $b^{p} \geq 0.9$, a high value, no equilibria has an $H H I^{\infty}$ close to 1 for any $\sigma \geq 0.5$.

Figure 7(a) presents a similar figure for $\rho$-homotopy paths for different level of $b^{p}$ (the $b^{p}=0$ plot matches BDK1 Figure 2, Panel A), with the other parameters at their illustrative values, including $\sigma=1$. Moving from left to right in the figure is associated with larger LBD effects. For all $\rho$ and for all $b^{p}$, there is an accommodative equilibrium $\left(H H I^{\infty}=0.5\right)$ (i.e., for each $b^{p}$ there is a line that follows the red line in the figure), while, for $b^{p}=0$ and $\rho \leq 0.8$, there are also equilibria where exit occurs and the SELPM equilibrium correspondence has (in this dimension) two disconnected loops. As $b^{p}$ increases, the geometry changes. The loops with the highest $H H I^{\infty}$ are eliminated as soon as $b^{p} \geq 0.05$, and the loops covering lower values of $H H I^{\infty}$ contract to cover a smaller range of $\rho$, disappearing entirely for $b^{p}>0.3$ so that, for all $\rho$, only a unique accommodative equilibrium exists.

Figure $7(b)$ classifies the equilibria into accommodative, AELPM and non-AELPM SELPM equilibria, where the latter two groups are also broken down into whether the equilibrium 
meets BDK2's definition of an aggressive equilibrium ${ }^{23}$ Appendix C.2 shows a similar classification for the $\sigma$-homotopy equilibria, and two patterns hold in both plots. First, all of the equilibria are either accommodative or SELPM (i.e., for these parameters the classificiation is exhaustive). In contrast, there are equilibria that are neither accommodative nor aggressive (i.e., some are unclassified using the aggressive/accommodative classification). Second, AELPM equilibria tend to have lower $H H I^{\infty}$ values than non-AELPM SELPM equilibria, a result which is worth briefly explaining. In equilibria where duopoly prices are exceptionally low, monopoly is very likely to result $\left(H H I^{\infty}\right)$ but it is also possible that firms will want to exit in symmetric states with low know-how. In this case, exit may be followed by re-entry, because both firms could leave at the same time, and these equilibria will not be AELPM, but can be SELPM.

If all equilibria are accommodative or SELPM, a claim consistent with our classification of the homotopy equilibria, then our recursive algorithm can prove whether an accommodative equilibrium is the unique equilibrium. Figure 8 shows the results of applying the algorithm for a grid of values, in steps of 0.05 , of $(\rho, \sigma)$ for different levels of $b^{p}$. The only gridpoints for which neither accommodative nor SELPM equilibria exist are $(\rho=1, \sigma \leq 0.65)$, where there is little product differentiation and no LBD, so that firms always have high costs. For these parameters, equilibrium profits are low in every state and there can be exit even in state $(M, M)$.

For the remaining combinations of parameters, there is a clear pattern. For $b^{p}=0$, accommodative and SELPM equilibria co-exist over a wide range of the parameter space. Accommodative equilibria are unique only when there is a lot of product differentiation or LBD is limited (and differentiation is not too low) ${ }^{24}$ As $b^{p}$ increases, the range of parameters with a unique accommodative equilibrium expands, whereas the range that supports SELPM equilibria shrinks. The changes are most dramatic for low $\rho$ : for example, when $\rho=0$ (costs fall from 10 to zero with one sale), SELPM equilibria can be supported for $\sigma \leq 1.05$ with $b^{p}=0$, but the threshold falls to $\sigma \leq 0.85$ when $b^{p}=0.3$. For the highest levels of $b^{p}$, SELPM equilibria only exist when product differentiation is limited, and SELPM and accommodative

\footnotetext{
${ }^{23}$ The equilibrium is aggressive if $p_{1}(\mathbf{e})<p_{1}\left(e_{1}, e_{2}+1\right), p_{2}(\mathbf{e})<p_{2}\left(e_{1}, e_{2}+1\right)$, and $\lambda_{2}(\mathbf{e})<\lambda_{2}\left(e_{1}, e_{2}+1\right)$ for some state $\mathbf{e}=\left(e_{1}, e_{2}\right)>(0,0)$ with $e_{1}>e_{2}$, where $\lambda$ is the probability of continuing. Recall that AELPM equilibria are SELPM equilibria where any exit from duopoly results in permanent monopoly.

${ }^{24}$ See Appendix B for a discussion of the evidence that there is only ever a single accommodative equilibrium.
} 

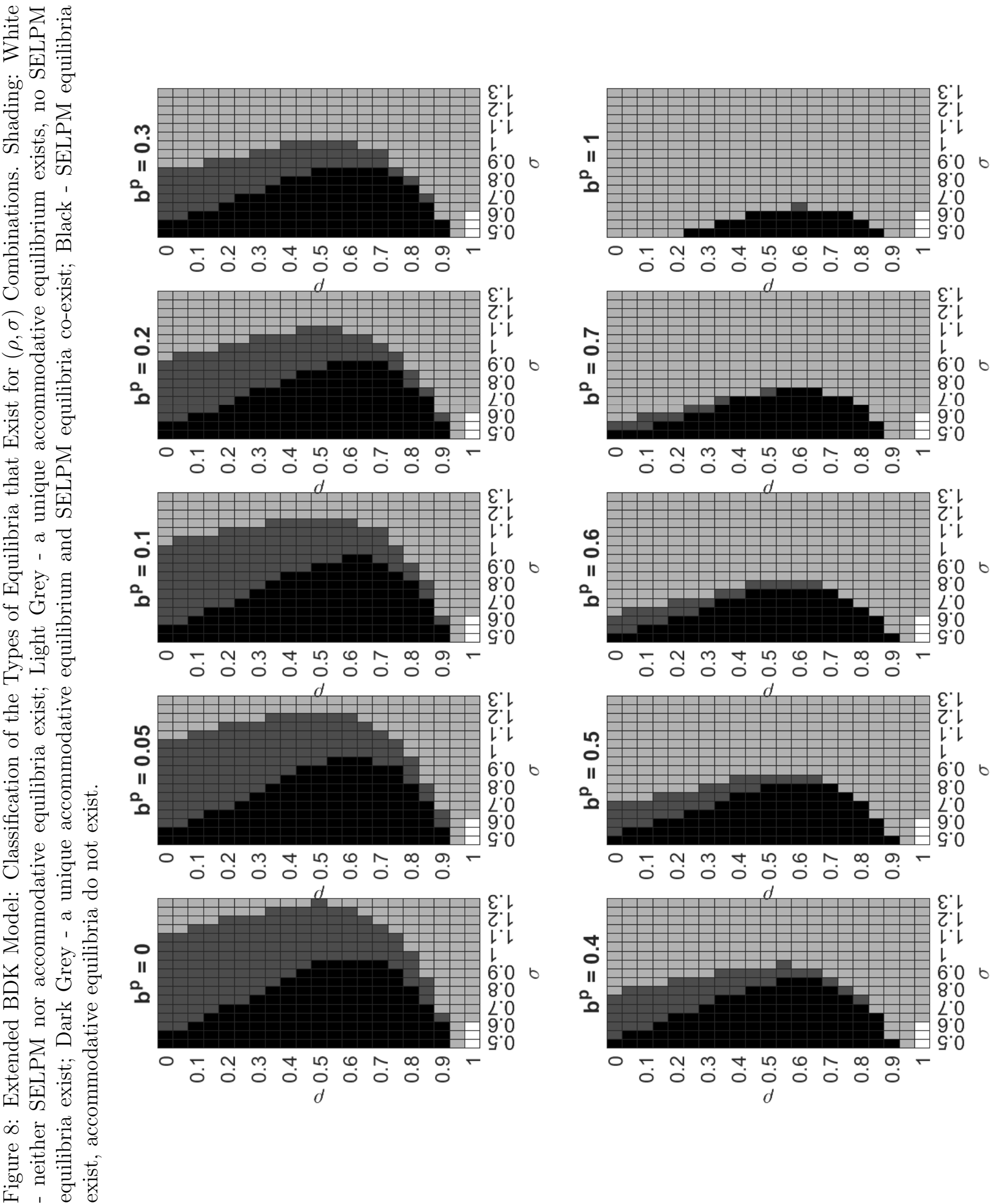
equilibria co-exist only for a narrow range of parameters.

\subsection{Prices and Welfare}

We now consider what happens to equilibrium prices and welfare as $b^{p}$ increases. Figure 9 presents expected long-run prices and the net present value of consumer surplus and total surplus for $\sigma$-homotopy plots, with $\rho=0.75$, and $\rho$-homotopy plots, with $\sigma=1$. For the $\rho$-homotopy plots, we measure welfare relative to the unique (accommodative) equilibrium when $b^{p}=1$ because the changes in the level of surplus caused by variation in marginal costs with $\rho$ would otherwise dominate the figures. We also draw the welfare plots for a subset of values of $b^{p}$ in order to reduce how many times lines cross, and we distinguish between accommodative equilibria (solid lines) and SELPM equilibria (dashed lines).

Consistent with the illustrative example, when parameters support both accommodative and SELPM equilibria, total surplus is maximized, and long-run prices are minimized, in the accommodative equilibrium. BDK2 conclude that equilibria tend to be quite efficient in the original BDK model, and this conclusion would appear to be strengthened when we allow for strategic buyer behavior to eliminate non-accommodative equilibria. Consumer surplus in an accommodative equilibrium tends to lie between the minimum and maximum consumer surplus of the SELPM equilibria, which is also consistent with the example. For any $\rho$ or $\sigma$, increasing $b^{p}$ tends to lower the NPV of consumer surplus in accommodative equilibria, as initial price competition is softened. It also tends to reduce total surplus when $\rho \leq 0.9$. On the other hand, when $0.9<\rho<1$, total surplus can increase in $b^{p}$ because marginal costs are high, and without strategic behavior there is a reasonably high probability that no sale will be made when a sale would be efficient. As a strategic buyer will be more likely to buy in lower know-how states to reduce future costs, this inefficiency can be offset 25 When both $\sigma$ and $b^{p}$ are small, there are many SELPM equilibria, but, because permanent monopoly is likely to arise quickly in all of them, they lead to very similar expected welfare numbers.

\footnotetext{
${ }^{25}$ For example, when $\rho=0.925$ and $b^{p}=0.2$, the probability that the buyer chooses the outside option in state $(1,1)$ is around 0.272 . When $b^{p}=1$, this probability falls to 0.241 (a $10 \%$ decrease).
} 

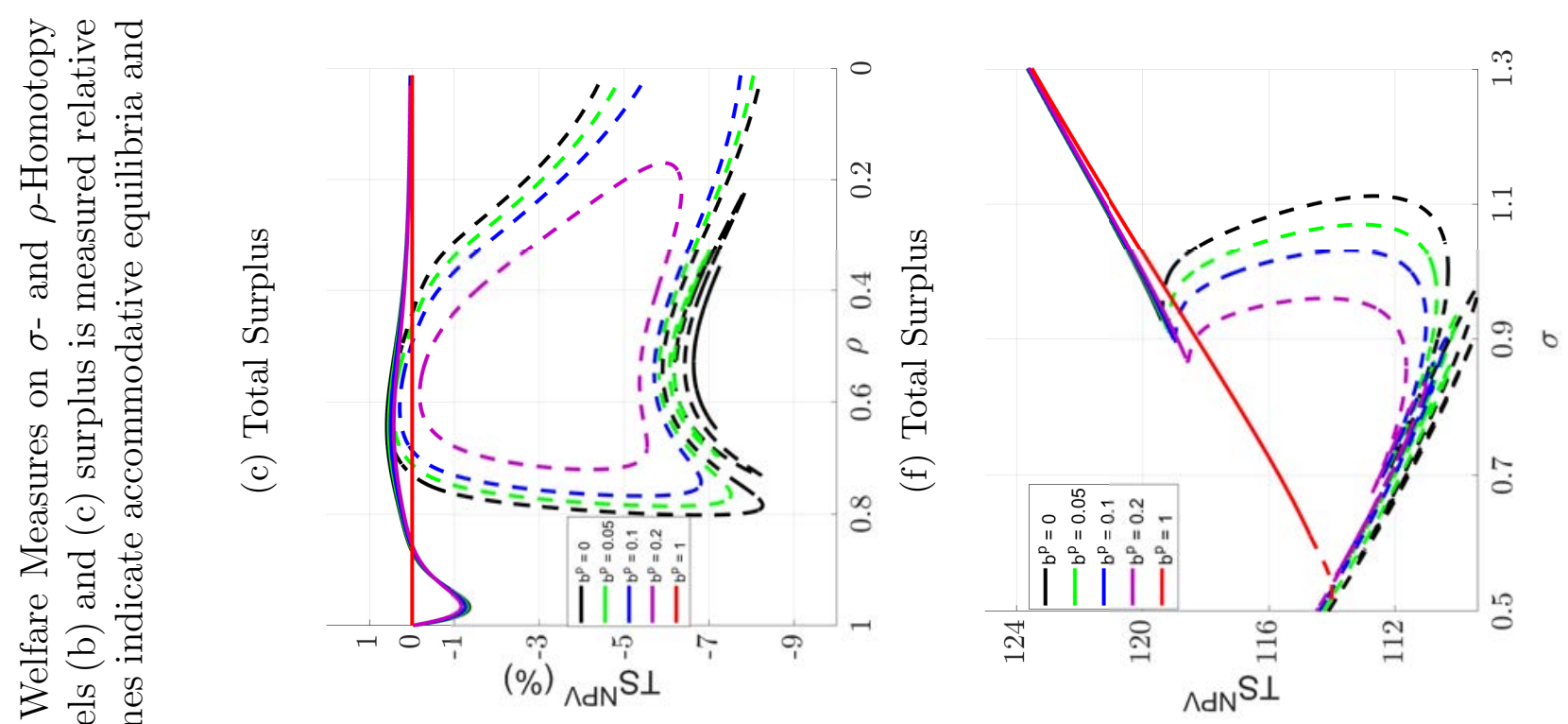

分

乙
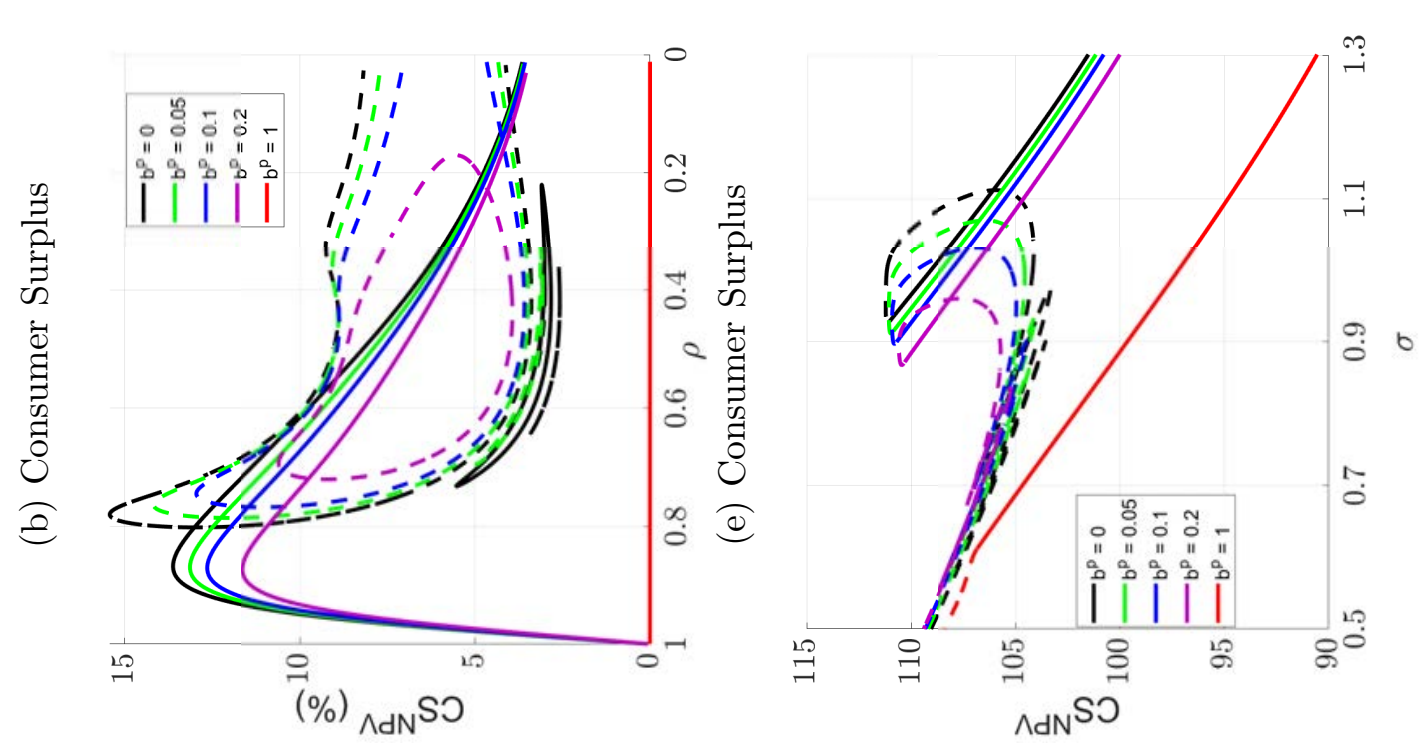

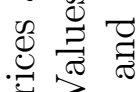

ᄃ

灵完

至

효

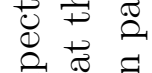

质豞

छ

흉

굴

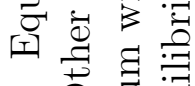

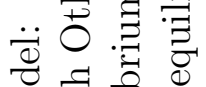

遍莺

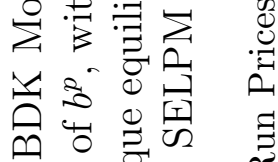

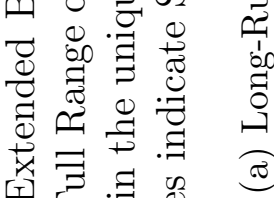

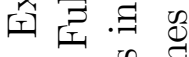

o
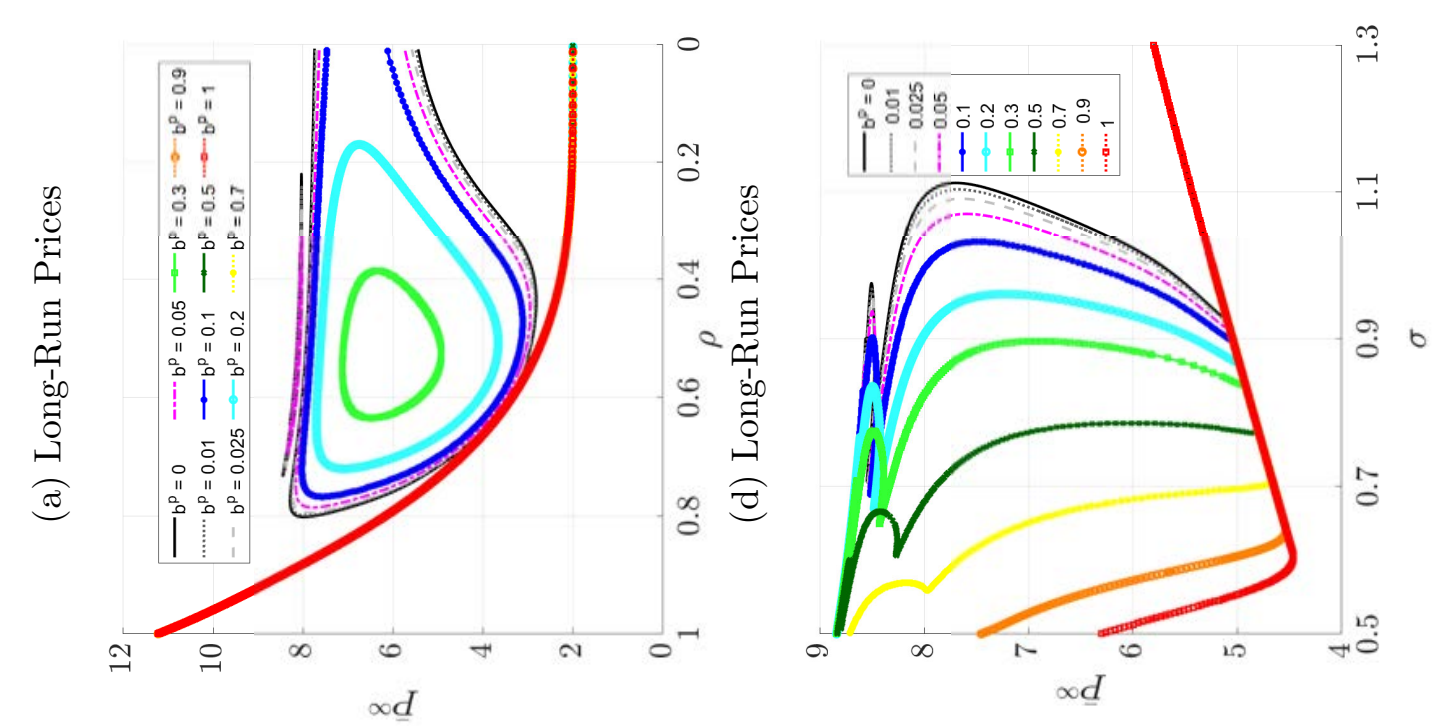


\section{Results for the Extended BDKS Model}

A feature of SELPM equilibria in the BDK model is that there are states where a buyer can guarantee long-run competition by making a particular purchase choice, providing a strong incentive for a strategic buyer to shift its demand even if it expects to receive a relatively small share of future surplus. We now consider the BDKS model, where there is no entry or exit, know-how can depreciate stochastically and a single purchase can never guarantee that competition will be sustained permanently. We find that, contrary to what one might expect, strategic buyer behavior eliminates multiplicity even more dramatically in this model.

\subsection{Differences Between the BDKS and BDK Models}

In the BDKS model there are always two active firms, with no entry or exit decisions. Once the buyer has made its purchase choice, which, unlike the BDK model, does not include an option not to purchase, know-how evolves according to

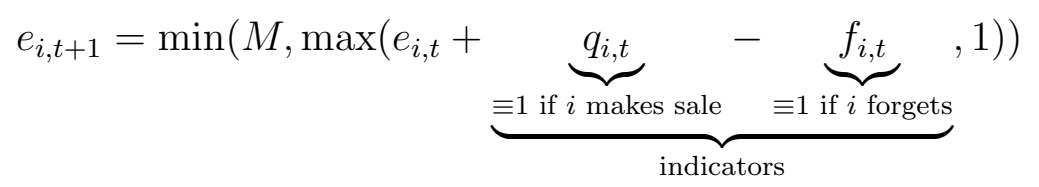

where $f_{i, t}$ is equal to one with probability $\Delta\left(e_{i}\right)=1-(1-\delta)^{e_{i}}$ where $\delta \in[0,1]$ parameterizes the forgetting rate. $\sigma$ is assumed to be equal to 1 , with $(\rho, \delta)$ as the main parameters of interest. A central insight of the BDKS paper is that, because forgetting can move a firm up its cost curve, an increase in the rate of forgetting can have a quite different effect on equilibrium strategies than weaker learning-by-doing.

\subsection{BDKS Equilibria for Illustrative Parameters}

Table 2 reports strategies for a subset of states for three equilibria identified when $b^{p}=0$, $\rho=0.75$ (facilitating comparison with our BDK example) and $\delta=0.0275$. We will use these parameters in some of our discussion below ${ }^{26}$ The table also reports the state-specific

\footnotetext{
${ }^{26}$ Appendix $\mathrm{C}$ will report some corresponding analysis for $\rho=0.85$ and $\delta=0.0275$ which is one of the parameter values that BDKS focus on in their analysis. For these parameters there are two equilibria, which is unusual, and one of them is characterized as "flat with well", in the sense that the pricing functions are
} 
Table 2: Equilibria in the BDKS Model for $\delta=0.0275, \rho=0.75, b^{p}=0$.

\begin{tabular}{|c|c|c|c|c|c|c|c|c|c|c|c|}
\hline \multirow[b]{2}{*}{$e_{1}$} & \multirow[b]{2}{*}{$e_{2}$} & \multirow[b]{2}{*}{$c_{1}$} & \multirow[b]{2}{*}{$c_{2}$} & \multirow[b]{2}{*}{$\Delta_{1}$} & \multirow[b]{2}{*}{$\Delta_{2}$} & \multicolumn{2}{|c|}{$\frac{\text { Sideways Trench }}{H H I^{\infty}=0.5000260}$} & \multicolumn{2}{|c|}{$\frac{\text { Sideways Trench }}{H H I^{\infty}=0.5000259}$} & \multicolumn{2}{|c|}{$\frac{\text { Diagonal Trench }}{H H I^{\infty}=0.5209345}$} \\
\hline & & & & & & $p_{1}$ & $p_{2}$ & $p_{1}$ & $p_{2}$ & $p_{1}$ & $p_{2}$ \\
\hline 1 & 1 & 10 & 10 & 0.028 & 0.028 & -4.12 & -4.12 & -4.10 & -4.10 & -3.25 & -3.25 \\
\hline 2 & 1 & 7.50 & 10 & 0.054 & 0.028 & 4.86 & 7.52 & 4.86 & 7.52 & 5.05 & 7.65 \\
\hline 2 & 2 & 7.50 & 7.5 & 0.054 & 0.054 & 2.87 & 2.87 & 2.87 & 2.87 & 0.21 & 0.21 \\
\hline 3 & 1 & 6.34 & 10 & 0.080 & 0.028 & 6.22 & 8.87 & 6.22 & 8.87 & 6.61 & 8.96 \\
\hline 3 & 2 & 6.34 & 7.5 & 0.080 & 0.054 & 4.13 & 5.38 & 4.13 & 5.38 & 3.84 & 5.81 \\
\hline 3 & 3 & 6.34 & 6.34 & 0.080 & 0.080 & 4.61 & 4.61 & 4.61 & 4.61 & 1.34 & 1.34 \\
\hline 4 & 1 & 5.63 & 10 & 0.106 & 0.028 & 6.31 & 8.91 & 6.31 & 8.91 & 6.72 & 8.83 \\
\hline 4 & 2 & 5.63 & 7.50 & 0.106 & 0.054 & 4.65 & 6.01 & 4.65 & 6.01 & 5.29 & 7.01 \\
\hline 4 & 3 & 5.63 & 6.34 & 0.106 & 0.080 & 4.71 & 5.25 & 4.71 & 5.25 & 3.63 & 5.35 \\
\hline 4 & 4 & 5.63 & 5.63 & 0.106 & 0.106 & 4.93 & 4.93 & 4.94 & 4.94 & 1.67 & 1.67 \\
\hline 10 & 1 & 3.85 & 10 & 0.243 & 0.028 & 6.07 & 8.58 & 6.07 & 8.58 & 6.20 & 8.04 \\
\hline 10 & 2 & 3.85 & 7.5 & 0.243 & 0.054 & 4.91 & 6.05 & 4.91 & 6.05 & 5.59 & 6.39 \\
\hline 10 & 3 & 3.85 & 6.34 & 0.243 & 0.080 & 5.15 & 5.83 & 5.15 & 5.83 & 5.69 & 6.27 \\
\hline 10 & 8 & 3.85 & 4.22 & 0.243 & 0.200 & 4.99 & 5.13 & 4.99 & 5.13 & 4.35 & 5.73 \\
\hline 10 & 9 & 3.85 & 4.02 & 0.243 & 0.222 & 5.01 & 5.07 & 5.01 & 5.07 & 3.15 & 4.41 \\
\hline 10 & 10 & 3.85 & 3.85 & 0.243 & 0.243 & 5.04 & 5.04 & 5.04 & 5.04 & 2.44 & 2.44 \\
\hline 29 & 1 & 3.25 & 10 & 0.555 & 0.028 & 5.90 & 8.37 & 5.90 & 8.37 & 5.60 & 7.51 \\
\hline 29 & 2 & 3.25 & 7.5 & 0.555 & 0.054 & 4.81 & 5.79 & 4.81 & 5.79 & 5.06 & 5.66 \\
\hline 30 & 1 & 3.25 & 10 & 0.567 & 0.028 & 5.90 & 8.37 & 5.90 & 8.37 & 5.66 & 7.60 \\
\hline 30 & 2 & 3.25 & 7.5 & 0.567 & 0.054 & 4.81 & 5.79 & 4.81 & 5.79 & 5.07 & 5.72 \\
\hline
\end{tabular}

Notes: $c_{i}, p_{i}, \Delta_{i}$ are the marginal costs, equilibrium price and probability of forgetting for firm $i$. $H H I^{\infty}$ is the expected long-run value of the HHI.

probabilities that a firm forgets $(\Delta)$. Firms set negative prices in state $(1,1)$ in all of the equilibria as they compete to get an advantage. The equilibria differ in strategies (and values) in all states, rather than just in a subset of states with low know-how, because, for $\delta>0$, there is always the possibility that the game will eventually transition to any other state in any equilibrium. The same logic implies that there are no absorbing states.

The first two equilibria, which have very similar prices except in state $(1,1)$, are characterized by a "sideways trench" where the price of the leading firm drops when its rival moves from $e_{j}=1$ to $e_{j}=2$, but then, if the laggard gains additional know-how, the leader's price increases even though the laggard's costs are falling. In the third equilibrium, the firms set low prices when they are symmetric (i.e., when a sale may cause leadership to switch from one firm to the other) and we describe this equilibrium as a "diagonal trench". Despite the relatively flat across the know-how space except that the firms set much lower prices in state $(1,1)$. 
differences in the strategies, each of the equilibria has an unconcentrated market structure in the long-run. 27

Figure 10(a) and (b) shows the $H H I^{\infty}$ and $P^{\infty}$ values implied by the equilibria on $b^{p_{-}}$ homotopy paths from the baseline equilibria. The diagonal trench and one of the sideways trench equilibria are connected on a single path which does not pass $b^{p}=0.068$. On the other hand, the path from the other sideways trench equilibrium continues to $b^{p}=1$, with $H H I^{\infty}$ remaining very close to 0.5 . In contrast to the BDK model, $P^{\infty}$ varies as $b^{p}$ increases as equilibrium price levels in all states, and the probability that the game is in a particular state, change continuously.

Figure 10(d) and (e) shows how firm 1's demand and its incentives change in state $(3,1)$, holding seller prices in all states fixed at their $b^{p}=0$ equilibrium values ${ }^{28}$ As the sideways trench equilibria are so similar, we only show one demand picture. In both cases, there is a noticeable shift of demand away from firm 1 as $b^{p}$ rises, and they are larger than the shifts in the Mid-HHI and accommodative equilibria in our BDK example. For $b^{p}=0$ the advantagedenying incentives in all of the equilibria are large relative to the advantage-building incentives, and they fall significantly as $b^{p}$ rises ${ }^{29}$ On the other hand, and unlike in our BDK example, the advantage-building incentives increase for low values of $b^{p} \cdot 30$ The decrease in demand and the increase in the advantage-building incentive both contribute to the initial decrease in firm 1's equilibrium price as $b^{p}$ rises (Figure $10(\mathrm{c})$ ).

\footnotetext{
${ }^{27}$ In the BDK model, for all of the equilibria that we consider in this paper, the long-run HHI is either 0.5 or 1 , and $H H I^{\infty}$ is equal to the weighted average of these outcomes. In the BDKS model all states have positive probability in the long-run when $\delta>0$.

${ }^{28}$ Even though buyers do not have the option to purchase in the BDKS model, we continue to define the advantage-building incentives as the difference between firm 1's continuation values when firm 1 makes a sale and the continuation value if there was to be no sale, and the advantage-denying incentive as the difference between firm 1's continuation value if there was to be no sale and the value if firm 2 makes the sale.

${ }^{29}$ While it is obviously not straightforward to compare the incentives across two different models, it is noticeable that the level of the advantage-denying incentive when $b^{p}=0$ is lower in these equilibria than in the High-HHI equilibrium of the BDK model, reflecting the fact that, in the BDKS model, there is no possibility of firm 1 gaining a permanent monopoly position.

${ }^{30}$ The most obvious intuition for this result is that the probability that a strategic buyer will buy from the laggard is decreasing when the leader has more know-how, because the buyer will expect it is more likely to want to buy from the leader in future periods, and this may make the accumulation of know-how more valuable for the leader as $b^{p}$ increases. On the other hand, once buyers are quite strategic, the probability that the leader will be able to maintain a significant advantage will fall, decreasing the advantage-building incentive.
} 


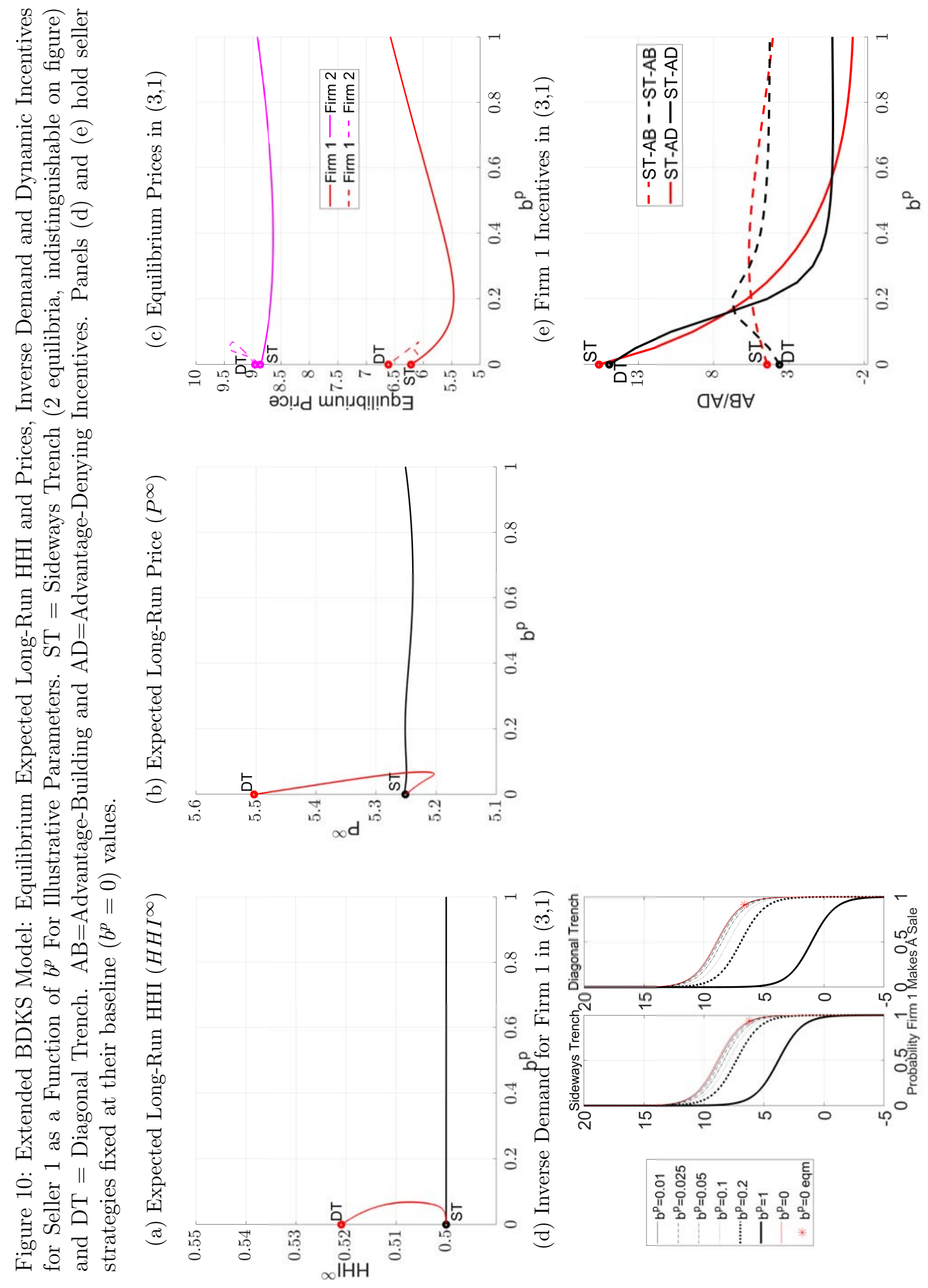


Figure 11: Extended BDKS Model: Number of Equilibria for $b^{p}=0$

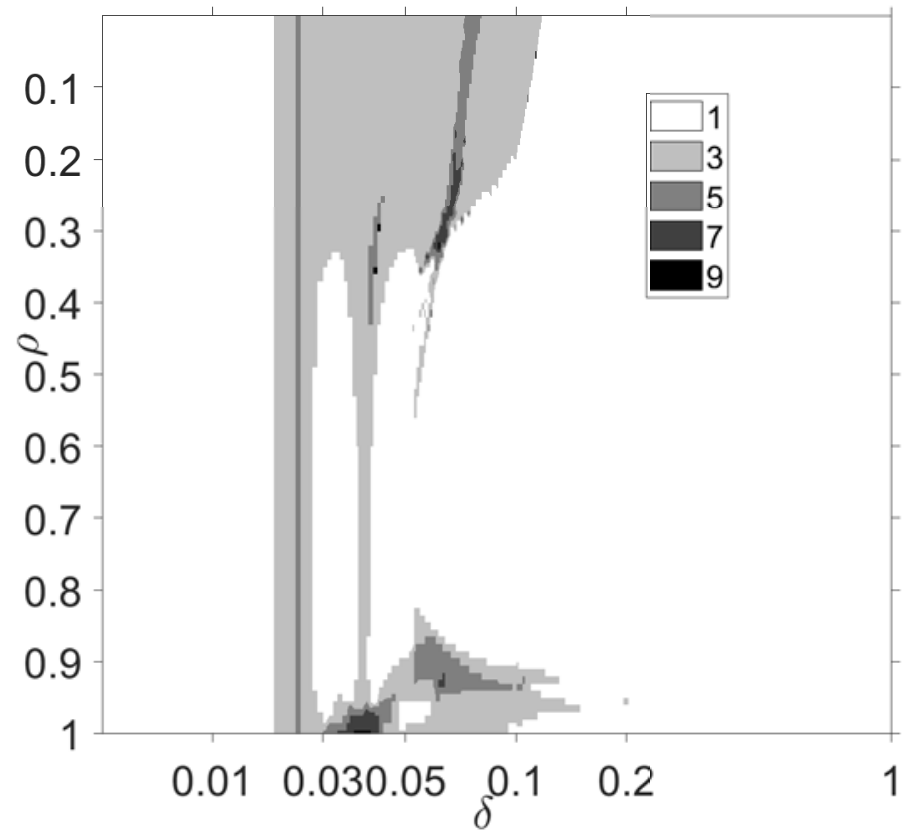

\subsection{Existence of Multiple Equilibria in the Extended BDKS Model}

As there are no absorbing terminal states when $\delta>0$, it is not possible to use a recursive algorithm to establish whether equilibria of a particular type exist ${ }^{31}$ We therefore follow BDKS in identifying the set of equilibria by using a sequence of $\delta$ - and $\rho$-homotopies to crisscross the parameter space for different discrete values of $b^{p}$. We also check that our results are consistent with $b^{p}$-homotopies that begin from multiple equilibria identified when $b^{p}=0$. The details of our implementation of the homotopy algorithm are given in Appendix A.

Figure 11 shows the number of equilibria that we identify when $b^{p}=0$ for different $(\rho$, $\delta)$. Even though the gridpoints may not be exactly the same, the figure is almost exactly identical to BDKS's Figure 2 except in a small area where $\rho>0.97$ and $\delta$ is around 0.04, where we identify some additional equilibria. There are multiple equilibria for a range of values of $\rho$ when $\delta$ lies between 0.02 and 0.15 , values that imply probabilities of forgetting when $e_{i}=m=15$ of 0.26 and 0.91 respectively. When the probability of forgetting is above 0.5 , it is not possible, even for a strategic monopsonist, to maintain both firms at the bottom of their learning curves for a sustained period.

\footnotetext{
${ }^{31}$ If $\delta=0$, backwards induction can be used to prove uniqueness of an equilibrium. The argument is similar to the one that we describe for accommodative equilibria in the BDK model in Appendix B, but it is simplified because one firm must make a sale.
} 
Figure 12: Extended BDKS Model: Number of Equilibria for $b^{p}>0$

(a) $b^{p}=0.01$

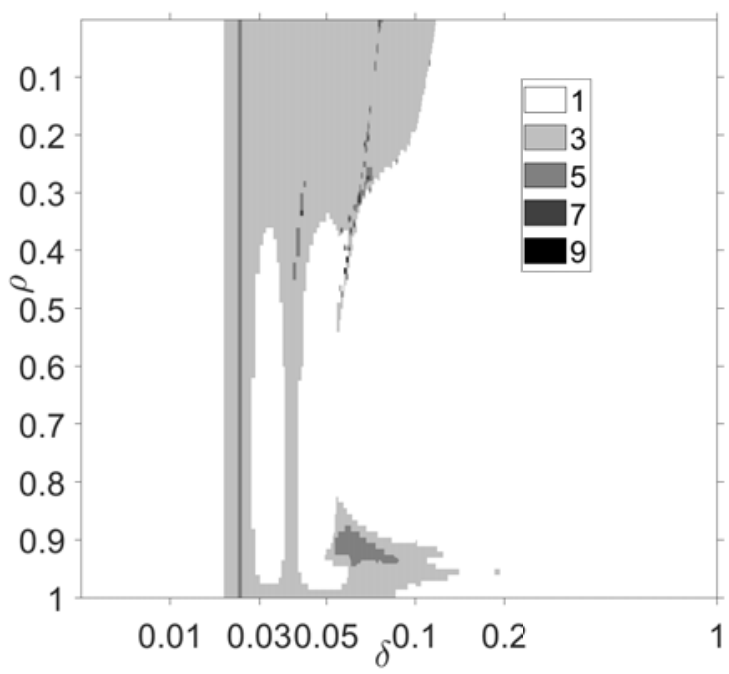

(c) $b^{p}=0.1$

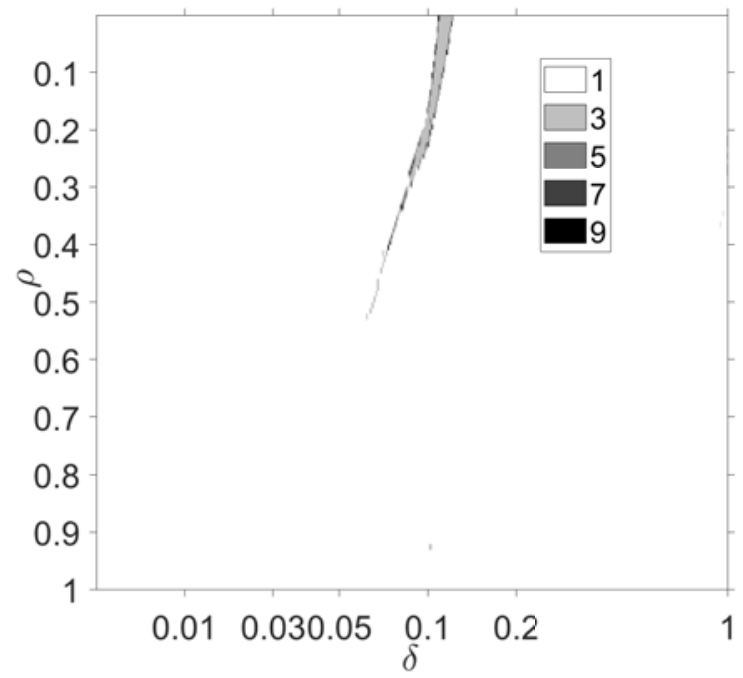

(b) $b^{p}=0.05$

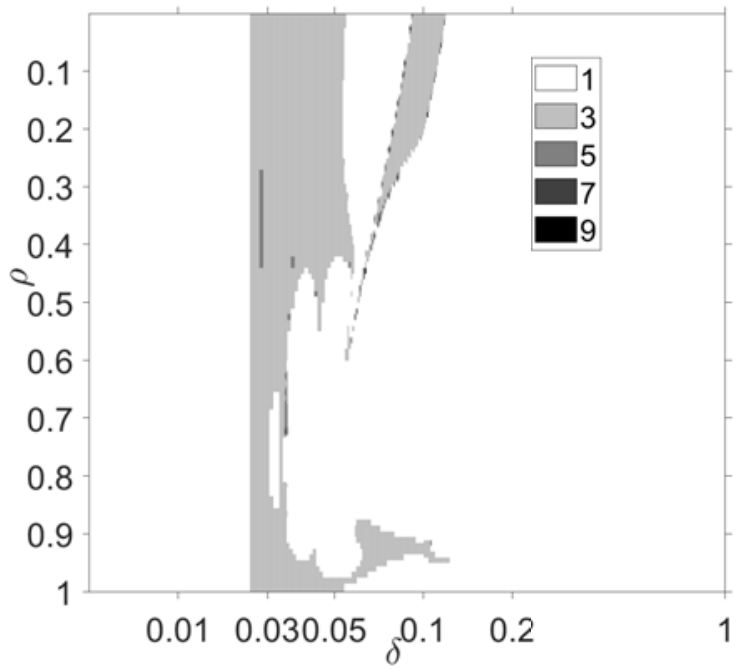

(d) $b^{p}=0.2$

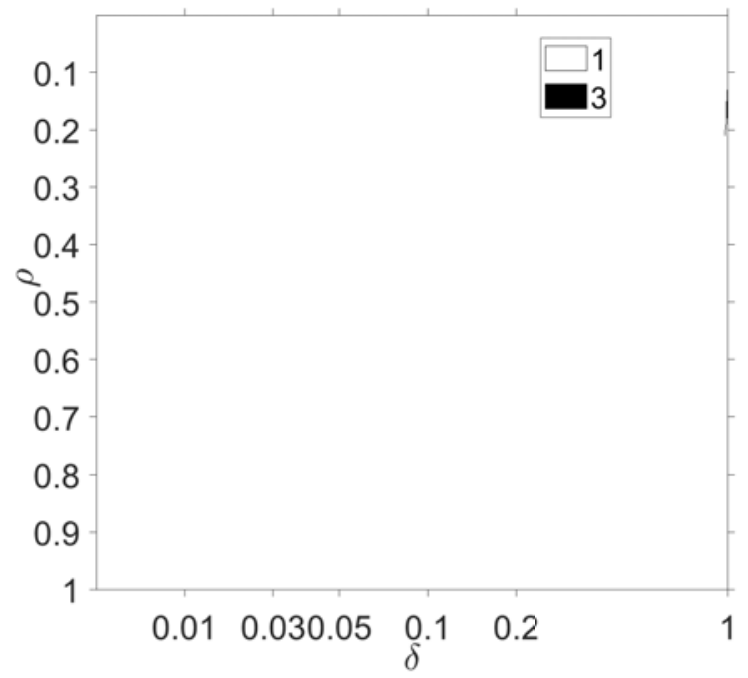

Figure 12 show the number of equilibria for the same gridpoints for $b^{p}$ equal to $0.01,0.05$, 0.1 and 0.2 . We find no multiplicity when $b^{p}=1$, so we do not show that figure. While there are a few parameters that have more equilibria when $b^{p}=0.05$ than when $b^{p}=0$, the general pattern is that multiplicity is eliminated quite rapidly as $b^{p}$ rises. When $b^{p}=0.1$ multiplicity is common only in a small sliver of the parameter space which is associated with parameters that are quite extreme in the sense they imply dramatic LBD $(\rho=0.2$ implies that $c(1)=10$ and $c(2)=2$ ) and a high probability of forgetting (if $\delta=0.1$, a firm with $e_{i}=5$ forgets with probability 0.41$){ }^{32}$ For $b^{p}=0.2$ we only find multiplicity for some extremely high values of $\delta$

\footnotetext{
${ }^{32}$ We also identify a few gridpoints with multiplicity around $\delta=0.1$ and $\rho=0.92$, and $\delta=0.97$ and $\rho=0.35$.
} 
where it is unlikely that a firm will be able to get more than one step down the cost curve. Appendix C.4 presents two $b^{p}$-homotopy plots that are consistent with the typical elimination of equilibria as $b^{p}$ rises and the existence of examples where the number of equilibria can increase for low $b^{p}$.

\subsection{Market Structure, Price and Welfare}

Figure 13 shows how expected long-run market concentration and average prices, and the NPV of consumer and total surplus, measured relative to surplus when $b^{p}=1$, for a game starting at $(1,1)$, vary with $\delta$ and $b^{p}$, based on $\delta$-homotopies, holding $\rho$ fixed at 0.75 . Similar figures, but with $\rho$ varying rather than $\delta$ (with $\delta$ held fixed at 0.05 , as the graphical results are clearer than with $\delta=0.0275$ ) are presented in Appendix C.5.

Consistent with our results for the number of equilibria, the folds and loops in the homotopy paths that exist for low $\delta$ when $b^{p}=0$ are eliminated as $b^{p}$ rises, so that there is a unique equilibrium for all $\delta$ for $b^{p} \geq 0.1$. For $\delta<0.6$, increases in $b^{p}$ are associated with lower long-run market concentration, consistent with the pattern identified in the BDK model that strategic buyers spread purchases to preserve long-run competition. However, whereas in the BDK model lower long-run concentration is associated with lower long-run prices, the possibility of forgetting means that spreading sales across sellers may raise long-run production costs. This leads to long-run prices being higher when $b^{p}=1$ than for some lower $b^{p}$ values when $\delta$ is between 0.03 and 0.1 , but the broad pattern is that more strategic buyer behavior tends to lower long-run prices as competition is preserved.

The feature that competition to defend or attain an advantage can last indefinitely in the BDKS model also affects the welfare comparisons. In the welfare plots we show a smaller number of $b^{p}$ lines to avoid clutter, and we compare surplus relative to the level when $b^{p}=1$. For low values of $\delta$, such as $\delta=0.0275$, where there are multiple equilibria, the effect of raising $b^{p}$ on surplus depends on which equilibrium is considered. This was also true in the BDK model. Focusing on higher values of $b^{p}$, such as 0.1 , where there is always a single equilibrium for the parameters shown, increasing $b^{p}$ tends to lower consumer surplus and total surplus for $\delta<0.6$, although we note that the comparison is unclear around $\delta=0.23$

\footnotetext{
${ }^{33}$ The reduction in total surplus when $b^{p}$ increases is explained by the lack of an outside option, which
} 
Figure 13: Extended BDKS Model: Equilibrium Expected Long-Run HHI, Long-Run Average Prices and NPV Welfare with $\rho=0.75$. In panels (c) and (d) surplus is measured relative to the surplus in the unique equilibrium when $b^{p}=1$.

(a) Expected Long-Run HHI ( $\left.H H I^{\infty}\right)$

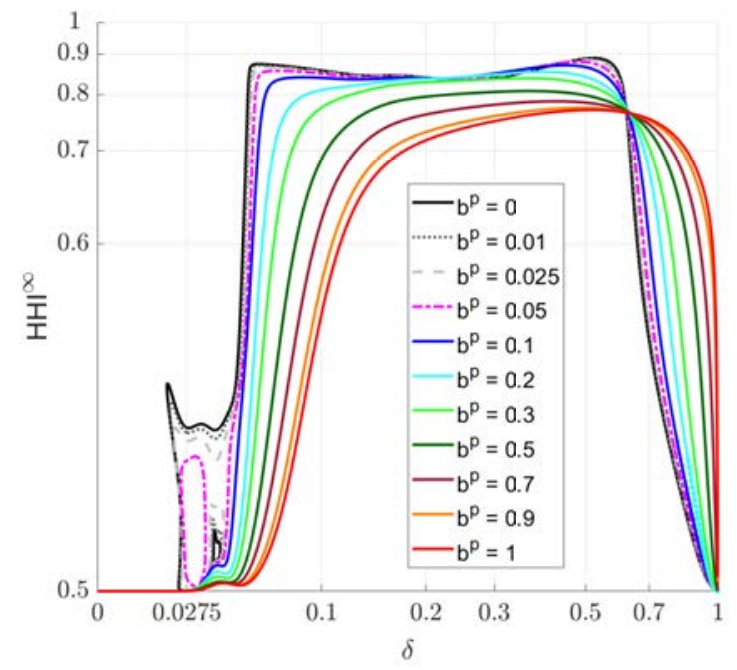

(c) NPV Consumer Surplus

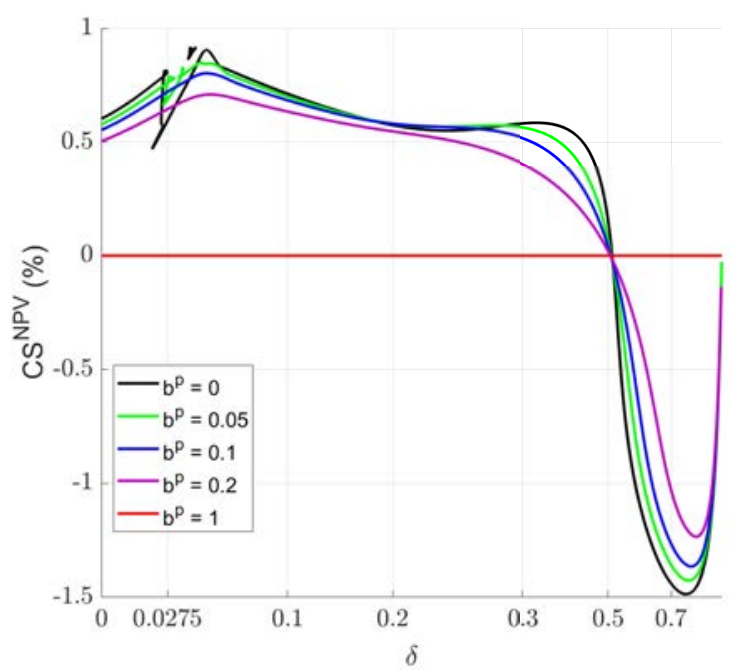

(b) Long-Run Expected Prices $\left(P^{\infty}\right)$

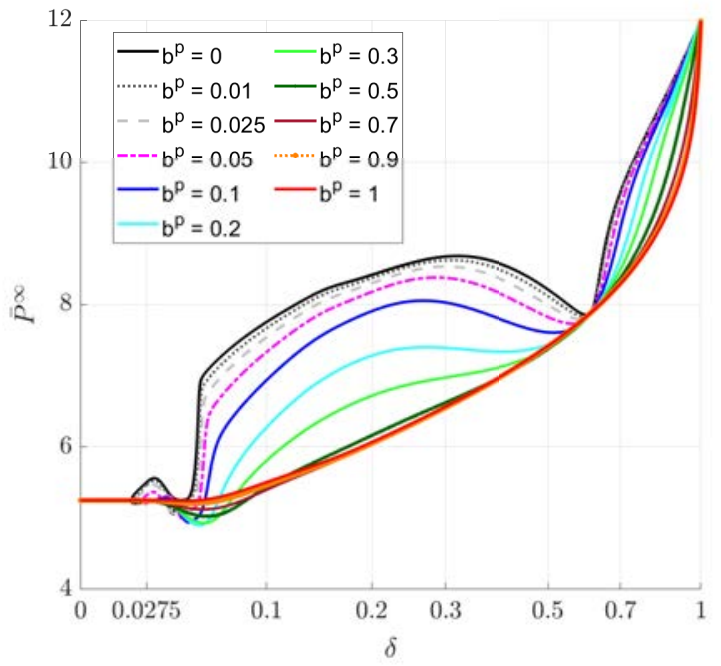

(d) NPV Total Surplus

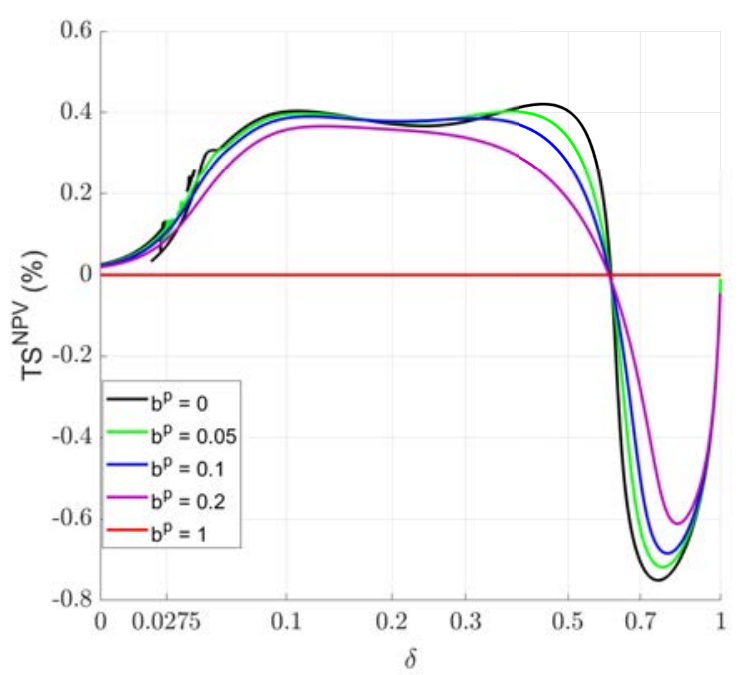


For $\delta>0.6$, patterns look different, because forgetting is rapid and marginal costs can only be kept low if purchases are focused on the same seller ${ }^{34}$ Therefore more strategic buyer behavior results in higher concentration, lower long-run prices and higher surplus.

As an aside, even though the lines in all of the figures intersect around $\delta=0.6$, it is not the case that seller strategies are identical for different $b^{p}$. For example, for low values of $b^{p}$, the equilibrium involves firms setting low prices when their states are symmetric (a narrow diagonal trench), whereas for higher values of $b^{p}$ there is there is a range of states where firms have different levels of experience but prices are very low. However, because the probability of forgetting is very high, the game will almost certainly be played in states where both firms have no or very low know-how, and for these states equilibrium prices are similar, leading to similar values of the outcome measures.

\section{Conclusion}

We have examined how equilibrium behavior and market outcomes change in well-known models where firms can benefit from learning-by-doing (LBD) when buyers partially internalize how their purchase decisions affect future buyer surplus. Our examination is motivated by the fact that most industries where LBD has been documented have at least some repeat buyers who we would expect to be forward-looking, whereas the existing literature has focused on the cases of short-lived atomistic buyers and monopsony.

The literature that has assumed that buyers are atomistic has emphasized that the existence of multiple equilibria is the norm rather than the exception, and that it is common for equilibria where competition tends to persist to coexist with equilibria where the industry develops to have a highly concentrated market structure. We find that even moderate degrees of forward-looking buyer behavior eliminate the multiplicity of equilibria for many parameter values, and that it is equilibria where competition is more likely to be sustained in the long-run that survive. As a result, strategic buyer behavior tends to lower prices in the long-run, even though the NPV of consumer surplus can be lowered as the incentive of firms to try to gain

implies that a strategic buyer will not increase the number of sales, and by the increase in long-run production costs when competition is preserved.

${ }^{34}$ For example, the probability that the firm forgets when it has acquired one level of know-how $\left(e_{i}=2\right)$ is 0.84 when $\delta=0.6$. 
an initial advantage is weakened.

We interpret our results as having at least two encouraging implications. One interpretation of the existing literature would be that, left to themselves, industries where firms can benefit from LBD might tend to tip towards inefficient dominance by a single firm, even when the underlying demand and cost structure could also support long-run competition. Our analysis suggests that this may be unlikely to happen in markets with even moderate buyer-side concentration. The existence of multiple equilibria also provides a well-known challenge, and often a deterrent, to conducting empirical and applied research using dynamic games. Our finding that equilibria with strategic buyers are typically unique, which is confirmed using a new approach in the context of the BDK model, suggests that adding strategic buyers may be a way to reduce multiplicity concerns, while also increasing the realism of these models.

An important direction for future research will be to identify whether these encouraging results are robust to including additional realistic extensions. For example, in most of the markets where strategic buyers are relevant, buyers may be asymmetric in their size or tastes, buyers and sellers may also be able to write contracts with multi-period options 35 , or prices may be set by some combination of a procurement auction and subsequent negotiation with the preferred bidder. It may be impractical to use homotopy methods to exhaustively search for multiple equilibria in models that include these features, making the types of recursive methodology, which we use in this paper to confirm the homotopy results, even more useful.

\footnotetext{
${ }^{35}$ One reason for preferring a model without commitment is that even if a buyer and seller sign a contract covering multiple periods when there is competition, there is some risk of ex-post opportunism by a seller that becomes a monopolist if there are non-contractible elements that firms care about.
} 


\section{References}

Alchian, A. (1963): "Reliability of Progress Curves in Airframe Production," Econometrica, 31(4), 679-693.

Anton, J. J., G. Biglaiser, and N. Vettas (2014): "Dynamic Price Competition with Capacity Constraints and a Strategic Buyer," International Economic Review, 55(3), 943958.

Asker, J., C. Fershtman, J. Jeon, and A. Pakes (forthcoming): "A Computational Framework for Analyzing Dynamic Procurement Auctions: The Market Impact of Information Sharing," RAND Journal of Economics.

Benkard, C. L. (2000): "Learning and Forgetting: The Dynamics of Aircraft Production," American Economic Review, 90(4), 1034-1054.

(2004): "A Dynamic Analysis of the Market for Wide-Bodied Commercial Aircraft," Review of Economic Studies, 71(3), 581-611.

Besanko, D., U. Doraszelski, and Y. Kryukov (2014): "The Economics of Predation: What Drives Pricing When There is Learning-by-Doing?," American Economic Review, 104(3), 868-97.

- (2019): "How Efficient is Dynamic Competition? The Case of Price as Investment," American Economic Review, 109(9), 3339-64.

Besanko, D., U. Doraszelski, Y. Kryukov, and M. Satterthwaite (2010): "Learning-by-Doing, Organizational Forgetting, and Industry Dynamics," Econometrica, $78(2), 453-508$.

Board, S., And A. Skrzypacz (2016): "Revenue Management with Forward-Looking Buyers," Journal of Political Economy, 124(4), 1046-1087.

Cabral, L. M., and M. H. Riordan (1994): "The Learning Curve, Market Dominance, and Predatory Pricing," Econometrica, 62(5), 1115-1115.

Chen, Y., V. F. Farias, and N. Trichakis (2019): "On the Efficacy of Static Prices for Revenue Management in the Face of Strategic Customers," Management Science, 65(12), $5535-5555$.

Dafny, L. S. (2005): "Games Hospitals Play: Entry Deterrence in Hospital Procedure Markets," Journal of Economics \&6 Management Strategy, 14(3), 513-542.

Dick, A. R. (1991): "Learning-By-Doing and Dumping in the Semiconductor Industry," Journal of Law and Economics, 34(1), 133-159.

ERICson, R., And A. PAKes (1995): "Markov-Perfect Industry Dynamics: A Framework for Empirical Work," Review of Economic Studies, 62(1), 53-82. 
Gans, J. S., And S. P. King (2002): "Exclusionary Contracts and Competition for Large Buyers," International Journal of Industrial Organization, 20(9), 1363-1381.

Gaynor, M., H. Seider, and W. B. Vogt (2005): "The Volume-Outcome Effect, Scale Economies, and Learning-by-Doing," American Economic Review, 95(2), 243-247.

Hörner, J., And L. SAmuelson (2011): "Managing Strategic Buyers," Journal of Political Economy, 119(3), 379-425.

Irwin, D. A., And P. J. Klenow (1994): "Learning-by-Doing Spillovers in the Semiconductor Industry," Journal of Political Economy, 102(6), 1200-1227.

Jerath, K., S. Netessine, and S. K. Veeraraghavan (2010): "Revenue Management with Strategic Customers: Last-Minute Selling and Opaque Selling," Management Science, $56(3), 430-448$.

KIm, M. (2014): "Strategic Responses to Used Goods Markets: Airbus and Boeing," Discussion paper, University of Oklahoma.

Lewis, T. R., And H. Yildirim (2002): "Managing Dynamic Competition," American Economic Review, 92(4), 779-797.

Lewis, T. R., And H. Yildirim (2005): "Managing Switching Costs in Multiperiod Procurements with Strategic Buyers," International Economic Review, 46(4), 1233-1269.

Lieberman, M. B. (1984): "The Learning Curve and Pricing in the Chemical Processing Industries," RAND Journal of Economics, 15(2), 213-228.

(1987): "Patents, Learning by Doing, and Market Structure in the Chemical Processing Industries," International Journal of Industrial Organization, 5(3), 257-276.

Loertscher, S., And L. M. Marx (2019): "Merger Review for Markets with Buyer Power," Journal of Political Economy, 127(6), 2967-3017.

Maskin, E., And J. Tirole (2001): "Markov Perfect Equilibrium: I. Observable Actions," Journal of Economic Theory, 100(2), 191-219.

Pakes, A., And P. MCGuire (1994): "Computing Markov-Perfect Nash Equilibria: Numerical Implications of a Dynamic Differentiated Product Model," RAND Journal of Economics, $25(4), 555-589$.

SAINI, V. (2012): "Endogenous Asymmetry in a Dynamic Procurement Auction," RAND Journal of Economics, 43(4), 726-760.

Sweeting, A., J. W. Roberts, And C. Gedge (2020): "A Model of Dynamic Limit Pricing with an Application to the Airline Industry," Journal of Political Economy, 128(3), 1148-1193.

Sweeting, A., X. TaO, And X. Yao (2019): "Dynamic Games with Asymmetric Information: Implications for Mergers," Discussion paper, University of Maryland. 
Thompson, P. (2001): "How Much Did the Liberty Shipbuilders Learn? New Evidence for an Old Case Study," Journal of Political Economy, 109(1), 103-137.

Thornton, R. A., And P. Thompson (2001): "Learning from Experience and Learning from Others: An Exploration of Learning and Spillovers in Wartime Shipbuilding," American Economic Review, 91(5), 1350-1368.

Zimmerman, M. B. (1982): "Learning Effects and the Commercialization of New Energy Technologies: The Case of Nuclear Power," Bell Journal of Economics, 13(2), 297-310. 